\title{
ARQUITECTURAS SIMBÓLICAS ORIENTADAS ASTRONÓMICAMENTE DURANTE EL NEOLÍTICO FINAL, EL CALCOLÍTICO Y LA EDAD DEL BRONCE EN EL SUR DE LA MESETA
}

\author{
ASTRONOMICALLY ORIENTED SYMBOLIC ARCHITECTURES DURING THE LATE \\ NEOLITHIC, CHALCOLITHIC AND BRONZE AGE IN THE SOUTH PLATEAU OF SPAIN
}

\author{
LUIS BENÍTEZ DE LUGO ENRICH \\ Dpto. de Prehistoria y Arqueología, Facultad de Filosofía y Letras. Universidad Autónoma de Madrid. Campus de Cantoblanco. 28049 Madrid. \\ Dpto. de Prehistoria y Arqueología, Facultad de Geografía e Historia (Centro Asociado de Ciudad Real). UNED. Centro Asociado de Ciudad \\ Real. Aptdo. de Correos 238. 13300 Valdepeñas (Ciudad Real). \\ Correo-e: luis.benitezdelugo@uam.es. ORCID: http://orcid.org/0000-0003-2000-6293. http://www.researcherid.com/rid/R-5521-2016 \\ CÉSAR ESTEBAN \\ Instituto de Astrofísica de Canarias. C/Vía Láctea s/n. 38200 La Laguna. Santa Cruz de Tenerife. Dpto. de Astrofísica. Facultad de Ciencias. \\ Universidad de La Laguna. Avda. Astrofísico Francisco Sánchez s/n. 38206 La Laguna. Santa Cruz de Tenerife. \\ Correo-e: cel@iac.es. ORCID: http://orcid.org/0000-0002-5247-5943
}

Resumen: Este trabajo presenta los resultados arqueoastronómicos de un proyecto interdisciplinar que estudia yacimientos de La Mancha fechados durante la Prehistoria Reciente. El centro ceremonial monumentalizado de Castillejo del Bonete muestra un marcador del amanecer del solsticio de invierno en la montaña más peculiar de su horizonte, así como alineaciones con este y otros eventos solares singulares, tales como el equinoccio y el solsticio de verano. Parece existir una correspondencia entre las orientaciones de algunas de las principales estructuras arquitectónicas del monumento y las que presentan dos de las galerías principales de una cueva natural que se encuentra justo debajo. Los marcadores y las orientaciones hacia el amanecer del solsticio de invierno pueden también estar presentes en otros sitios contemporáneos cercanos, como son el abrigo funerario del Cerro Ortega y la motilla del Azuer. Castillejo del Bonete constituye la primera evidencia de un marcador solar en un túmulo prehistórico de la península ibérica, lo que indica que su ubicación fue cuidadosamente elegida. Las alineaciones definidas por sus estructuras refuerzan su simbolismo astronómico. Los resultados de este estudio demuestran la importancia de los elementos astrales en el mundo funerario y religioso de la Prehistoria Reciente de La Mancha, en donde el orto del solsticio de invierno parece que tuvo un especial protagonismo.
Abstract: We present archaeoastronomical results of an interdisciplinary project to study Bronze Age and Chalcolithic in the Spanish region of La Mancha. We find that winter solstice sunrise was of special importance in the funerary - and perhaps religious - practises of these peoples. The impressive megalithic monumental complex of Castillejo del Bonete shows a remarkable marker of the winter solstice sunrise on the most peculiar mountain of its horizon as well as alignments with this and other singular solar events as equinox and summer solstice. There seems to be a correspondence between the orientations of some of the main architectural structures of the monument and the general arrangement of two of the main galleries of a natural cave that lies just beneath it. Markers and orientations to the winter solstice sunrise seem to be present in other nearby contemporary sites such as the necropolis of Cerro Ortega and the motilla of the Azuer. Castillejo del Bonete stands as the first evidence of a solar marker in a megalithic site of the Iberian Peninsula, indicating that the precise location of the monument was carefully chosen. The alignments defined by several of its structures further reinforce its astronomical symbolism. 
Palabras clave: Arqueoastronomía, túmulo funerario, motilla, solsticio de invierno, religión, arqueología funeraria, cambio climático.

\section{INTRODUCCIÓN}

¿Creían los habitantes de las llanuras manchegas, hace 4500 años, en una vida más allá de la muerte? ¿A qué tipo de dioses adoraban? ¿Cómo eran sus ritos? Estas preguntas tienen una difícil respuesta desde la ciencia, pero es posible aportar algo de luz al mundo de las creencias de aquellos lejanos antepasados a partir del estudio de la cultura material que nos han legado. Algunos de los indicios que permiten un acercamiento a la religiosidad prehistórica son las imágenes reflejadas en los utensilios que aquellas personas utilizaron, en sus pinturas o sus grabados rupestres, así como algunas de las características de sus construcciones. Se trata de secuencias inconexas y mudas de una narrativa mayoritariamente perdida.

Para muchas civilizaciones del pasado, los astros jugaron un papel fundamental en su mundo religioso; especialmente el Sol, símbolo universal del renacimiento tras la muerte y regulador del ciclo vital de la naturaleza. En los últimos años se ha extendido el análisis del contexto astronómico de los yacimientos arqueológicos, proporcionando resultados que han permitido avanzar en el conocimiento de aspectos culturales y simbólicos intangibles y descubrir que nuestros antepasados observaban los astros con atención, siguiendo sus movimientos y cambios de apariencia.

Hasta 2015 no se habían realizado investigaciones arqueoastronómicas en ningún yacimiento arqueológico de la provincia de Ciudad Real. El primer trabajo de este tipo se aplicó al denominado 'Santuario de Entrada' protohistórico del oppidum oretano Cerro de las Cabezas (Valdepeñas, Ciudad Real) (Esteban López y Benítez de Lugo Enrich 2016). En el presente trabajo se plantea realizar un estudio arqueoastronómico de yacimientos situados en el mismo ámbito territorial, pero con cronologías varios miles de años más tempranas, a partir del último cuarto de IV milenio.

\section{OBJETO DE ESTUDIO}

Castillejo del Bonete (Terrinches), Cerro Ortega (Villanueva de la Fuente), la motilla del Azuer (Daimiel) y Bocapucheros (Almagro) son enclaves de la provincia
Keywords: Archaeoastronomy, Monumental Barrow, Motilla, Winter Solstice, Religion, Funeral Archaeology, Climate Change.

de Ciudad Real que se encuentran en el borde meridional de la Meseta castellana y fueron utilizados en el IV y III milenios a.C. con fines funerarios (fig 1). No se debe pensar que fueron meros cementerios. Como se expondrá más adelante fueron lugares complejos, con múltiples aspectos que se encuentran pendientes de explicación.

Los tres primeros yacimientos arqueológicos mencionados cuentan con dataciones absolutas, que son:

- Cerro Ortega: 3341-3027 cal BC (Odriozola Lloret et al. 2016)

- Castillejo del Bonete: 2465-1565 cal BC (Benítez de Lugo Enrich et al. 2015a).

— Motilla del Azuer: 2200-1350 cal BC (López Sáez et al. 2014).

\subsection{Castillejo del Bonete}

Las excavaciones arqueológicas en el Castillejo del Bonete (Terrinches, Ciudad Real) han permitido descubrir un conjunto tumular prehistórico sin igual (fig. 2). Se localiza sobre el extremo meridional de un pequeño cerro y dominando un amplio horizonte despejado en su mitad sur de este a oeste.

En este lugar hasta el momento se han encontrado dos túmulos, aunque existen evidencias de que otros no han sido desenterrados aún. El principal, llamado Túmulo 1, es el más grande y se ubica sobre una cueva natural que presenta arte rupestre postpaleolítico y construcciones en su interior. Esta misma estructura muestra accesos en forma de corredores abocinados y también corredores de comunicación con otros túmulos o estructuras, alguno con más de veinte metros de longitud. Cazoletas excavadas en piedra, similares a otras encontradas en diferentes lugares sin contexto arqueológico, aparecen en el nivel de uso del Túmulo 2. Los materiales arqueológicos que se encuentran depositados en el lugar se localizan en pequeñas fositas o estructuras siliformes (Benítez de Lugo Enrich et al. 2014a). Esos objetos son de características muy diversas (Benítez de Lugo Enrich et al. 2015a). Entre ellos cabe destacar una abundante colección de piezas metálicas (Montero Ruiz et al. 2014), cerámicas (Fernández Martín et al. 2015), arte rupestre con restos humanos a 


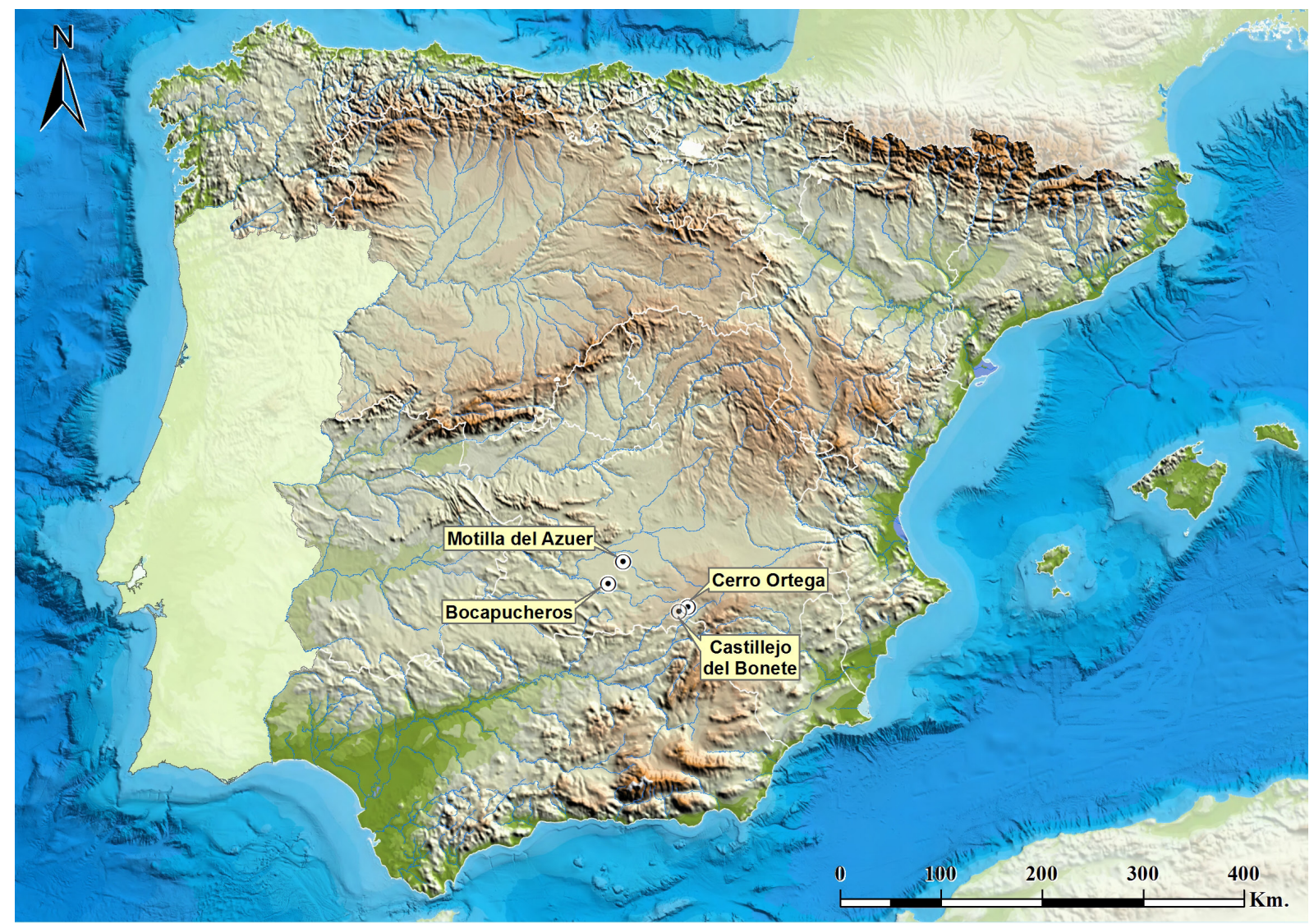

Figura 1. Mapa general de localización de los lugares estudiados.

sus pies (Martín et al. 2015a) y botones de marfil (Benítez de Lugo Enrich et al. 2015b), además de restos óseos (humanos o de fauna) y numerosos adornos personales: colgantes elaborados con concha marina, una colección con decenas de cuentas de hueso, madera fósil y variscitas verdes de diversas procedencias (Odriozola Lloret et al. 2016).

El repertorio de materiales encontrado en Castillejo del Bonete es semejante al que aparece en las motillas (Benítez de Lugo Enrich y Mejías Moreno, 2016). Los huesos humanos se han encontrado en diferentes formatos: dentro de tumbas (esqueletos con conexión anatómica) -en ocasiones dobles, como es el caso de la Tumba 4-, en depósitos secundarios de huesos retirados del enterramiento original una vez descarnados, o dispersos por todo el yacimiento. Esta última variable corresponde en general a huesos o fragmentos de hueso de pequeño tamaño, que aparecen por doquier de forma similar a como suelen aparecer en áreas cementeriales que han sido sometidas a repetidos movimientos de tierra. Aunque el estudio antropológico se encuentra en este momento pendiente de conclusión, es posible avanzar que el número de individuos localizados es relativamente escaso en relación con el largo período de tiempo en que este lugar fue utilizado. Parece evidente que no todos los individuos de la comunidad fueron enterrados aquí, sino solo algunos. De hecho, existe constancia de enterramientos en fosas y pithoi, no tumulares, en las proximidades (Benítez de Lugo Enrich 2014-2015: 199). En Castillejo del Bonete no se ha detectado por el momento ninguna sistemática en cuanto al área de localización de los enterramientos; se localizan tanto dentro de la cueva como al exterior, en el túmulo y su entorno. En definitiva, este fue un lugar utilizado durante mucho tiempo, en el que se enterraron difuntos y en donde esas tumbas fueron afectadas por sucesivos movimientos del terreno. Cabe añadir que los restos humanos que muestran conexión anatómica no llegan a media docena (fig. 3).

Sobre alguna de las tumbas, como es el caso de la número 4 antes citada, se encendió una hoguera encima de la capa de tierra que cubría a los muertos. El calor 


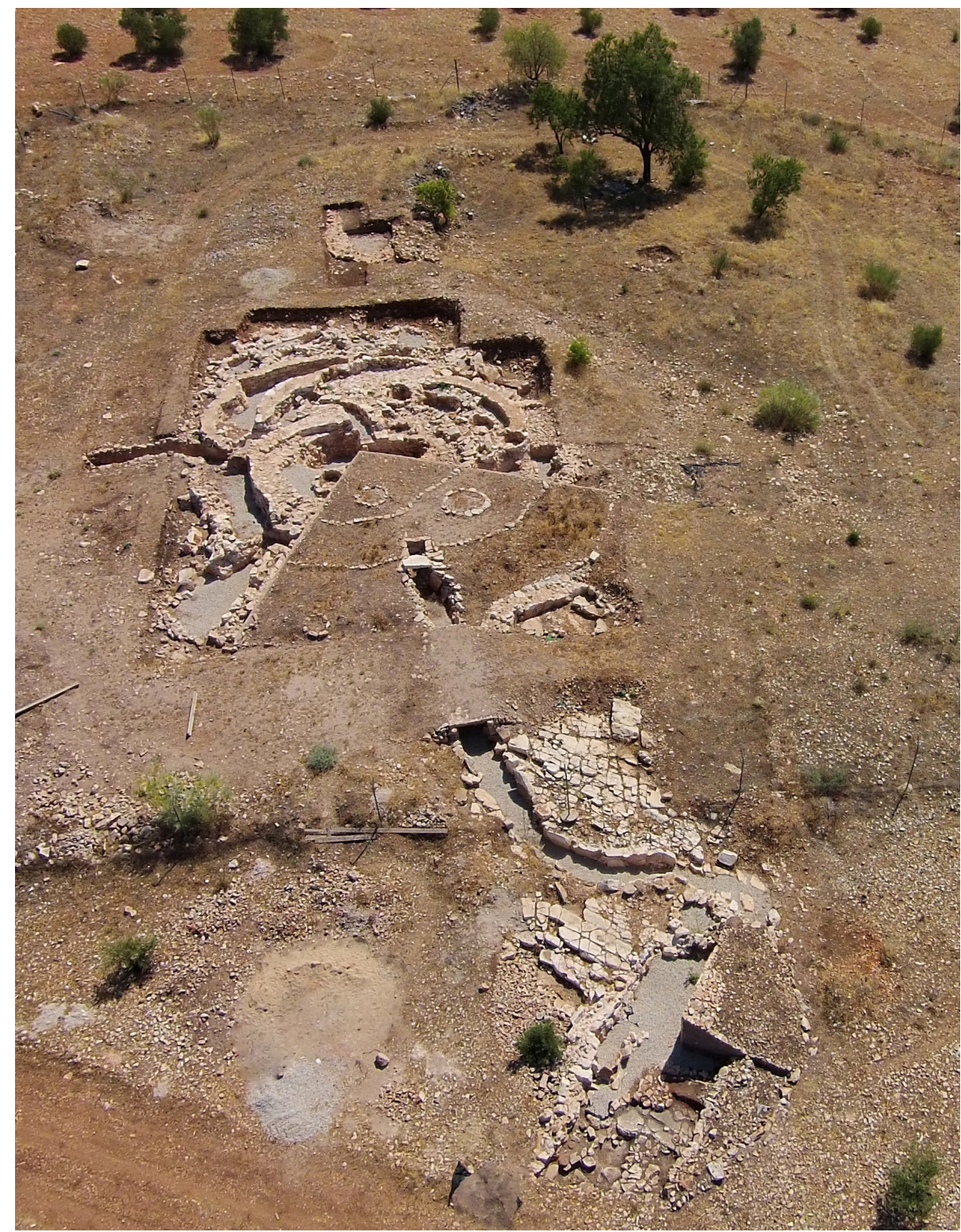

Figura 2. Vista aérea general de Castillejo del Bonete. alteró parte del contenido de la tumba, tostando parte de los esqueletos (Benítez de Lugo et al. 2014a: 167; lám. 18). En esa hoguera se clavó o arrojó una flecha, cuya punta tipo Palmela se recogió con el pedúnculo doblado entre las cenizas (Montero Ruiz et al. 2014: 116; fig. 6.1).

Algunas personas enterradas en este lugar del interior peninsular se alimentaron con proteína marina (Salazar García et al. 2013). Gutiérrez Sáez et al. (2000 y 2002) también plantean la presencia de fuegos rituales en otros enterramientos prehistóricos múltiples en La Mancha.
Castillejo del Bonete fue declarado Bien de Interés Cultural en 2014 (fig. 4).

Aunque por su forma exterior Castillejo del Bonete podría parecer una motilla, quedó demostrado en este caso que no existe acceso posible con los medios de la época al nivel freático (Benítez de Lugo Enrich et al. 2014b).

Con los datos disponibles es posible afirmar que Castillejo del Bonete fue un centro ceremonial monumentalizado situado sobre el borde mismo de la Meseta Sur, en el que los astros y los ancestros fueron utilizados como argumentos para transmitir un discurso que 


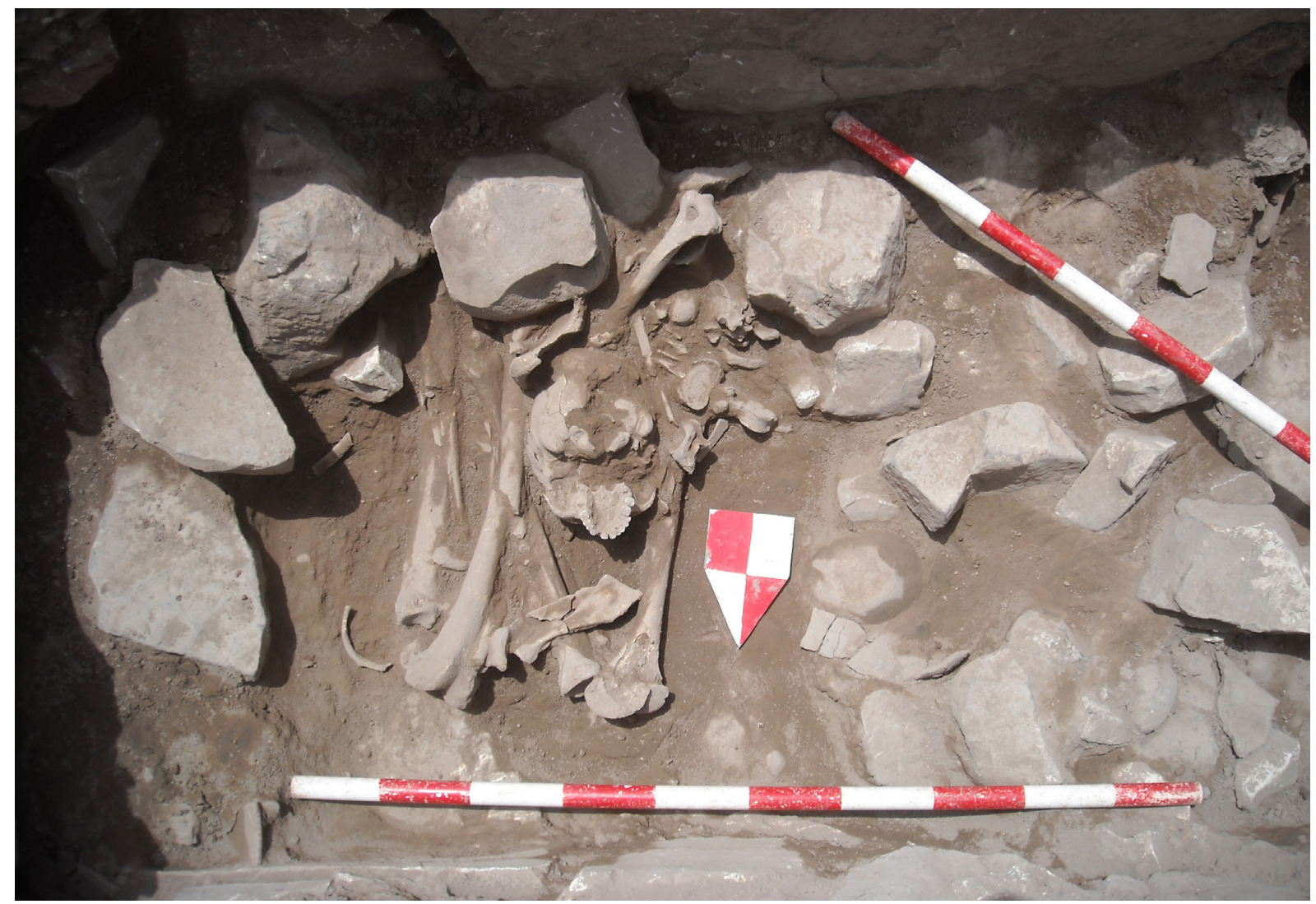

Figura 3. Tumba 5 de Castillejo del Bonete.

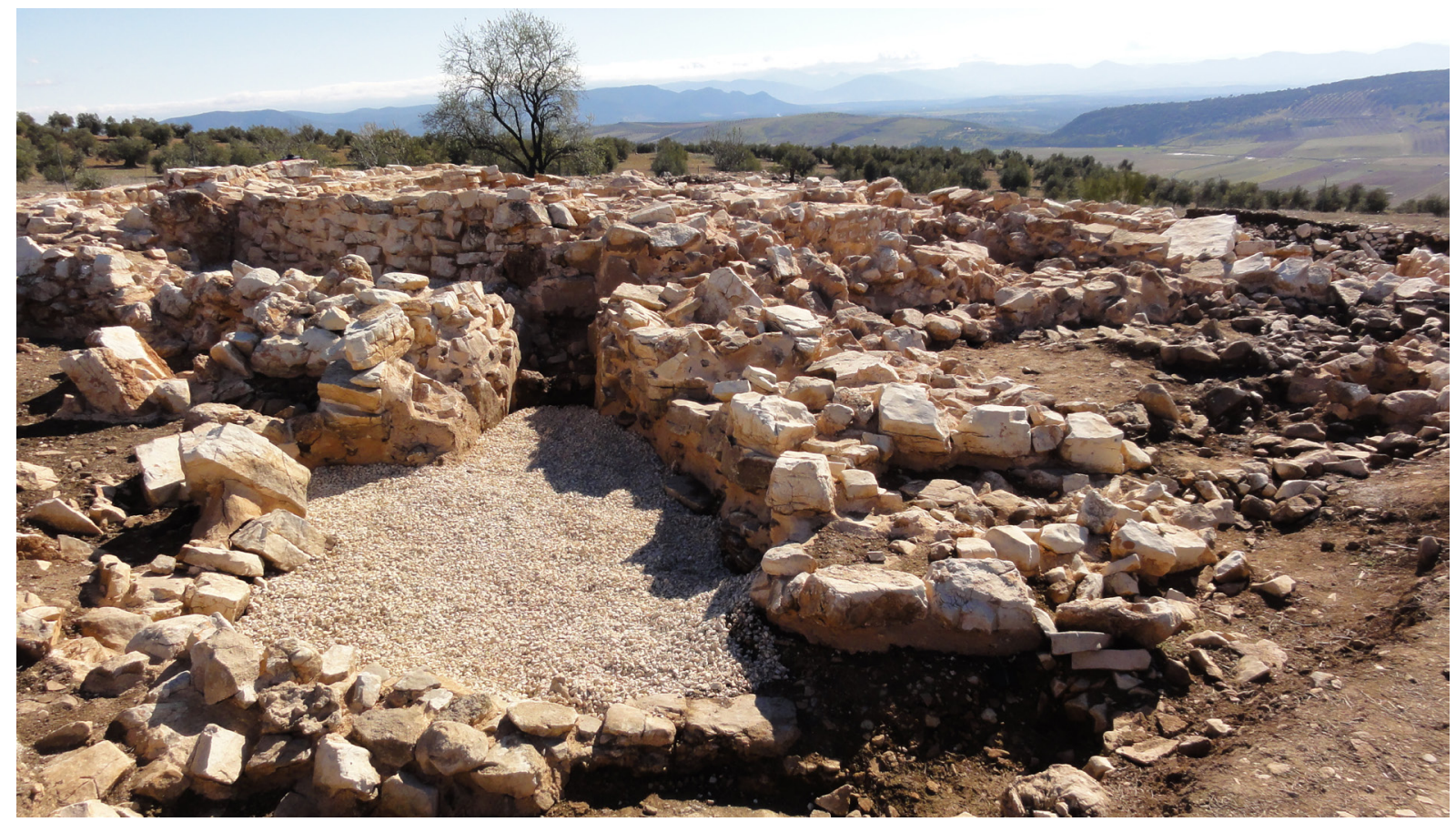

Figura 4. Corredor abocinado A de Castillejo del Bonete

ISSN: 1133-4525 ISSN-e: 2255-3924 


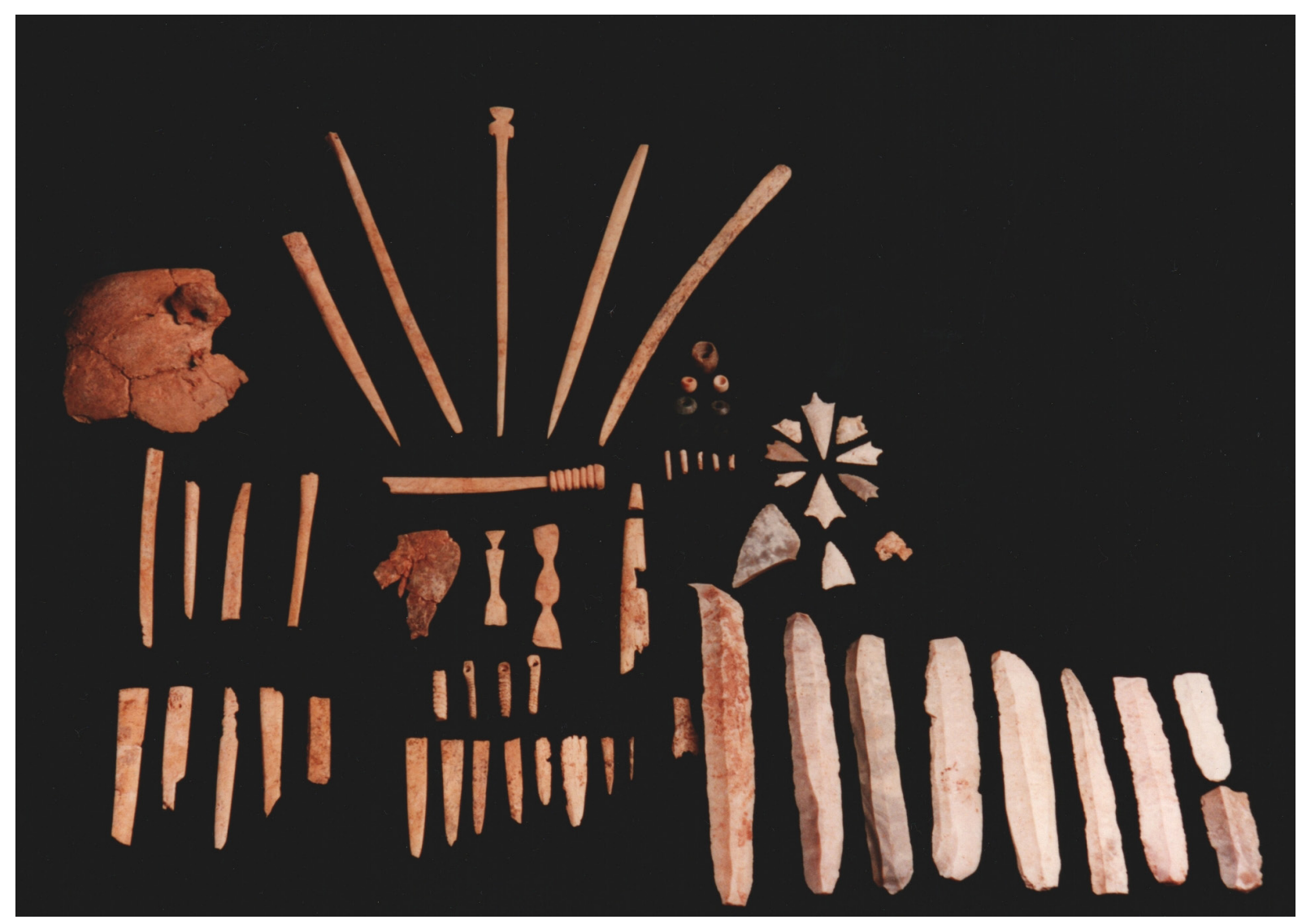

Figura 5. Materiales asociados a los enterramientos de Cerro Ortega.

giró, probablemente, en torno a la legitimidad sobre el territorio. Recientes dataciones indican que el lugar fue utilizado desde finales del IV hasta mediados del I milenios cal a.C. El monumento estuvo dotado de una alta carga simbólica y en el cual se desarrollaron ritos complejos que estamos empezando a desvelar. Los espacios arquitectónicos documentados no presentan evidencias de habitación, y sí las características habituales en túmulos prehistóricos. Castillejo del Bonete fue lugar de celebración (comida, bebida, depósito de objetos y acciones cuyo desarrollo es posible desvelar), muy visible desde la lejanía y, por último, dotado de un enorme interés arqueoastronómico, como veremos a continuación.

\subsection{Cerro Ortega}

Las excavaciones arqueológicas desarrolladas en el abrigo situado al pie del Cerro Ortega (Villanueva de la Fuente, Ciudad Real) fueron dirigidas por Bienvenido
Maquedano Carrasco y Carlos Barrio Aldea (Barrio Aldea y Maquedano Carrasco 2000). Sus estudios permitieron descubrir un depósito de huesos humanos sin conexión anatómica mezclados con abundantes restos de fauna (fig. 5). No se ha encontrado metal en el lugar.

El yacimiento fue adscrito a la cultura calcolítica por sus excavadores y a la neolítica por el Laboratorio de Antropología Forense y Paleopatología de la Universidad de Valencia, sin aportar argumentos a la datación en este último caso (Gil Pitarch et al. 1999; Polo Cerdá et al. 1999). En 2016 se publicó una primera datación absoluta de este yacimiento, que permite concretar su uso en el Neolítico final, a finales del IV milenio a.C. (vid. supra).

Los materiales arqueológicos no se encontraron en fosas de inhumación, sino enterrados en un estrato blando, relacionados con unas margas verdosas existentes en el corte de una pared de arenisca rojiza. Los restos humanos fueron dispuestos en esa especie de nicho o abrigo mediante acumulaciones selectivas distribuidas de forma intencionada: los huesos largos en una zona y los cráneos 


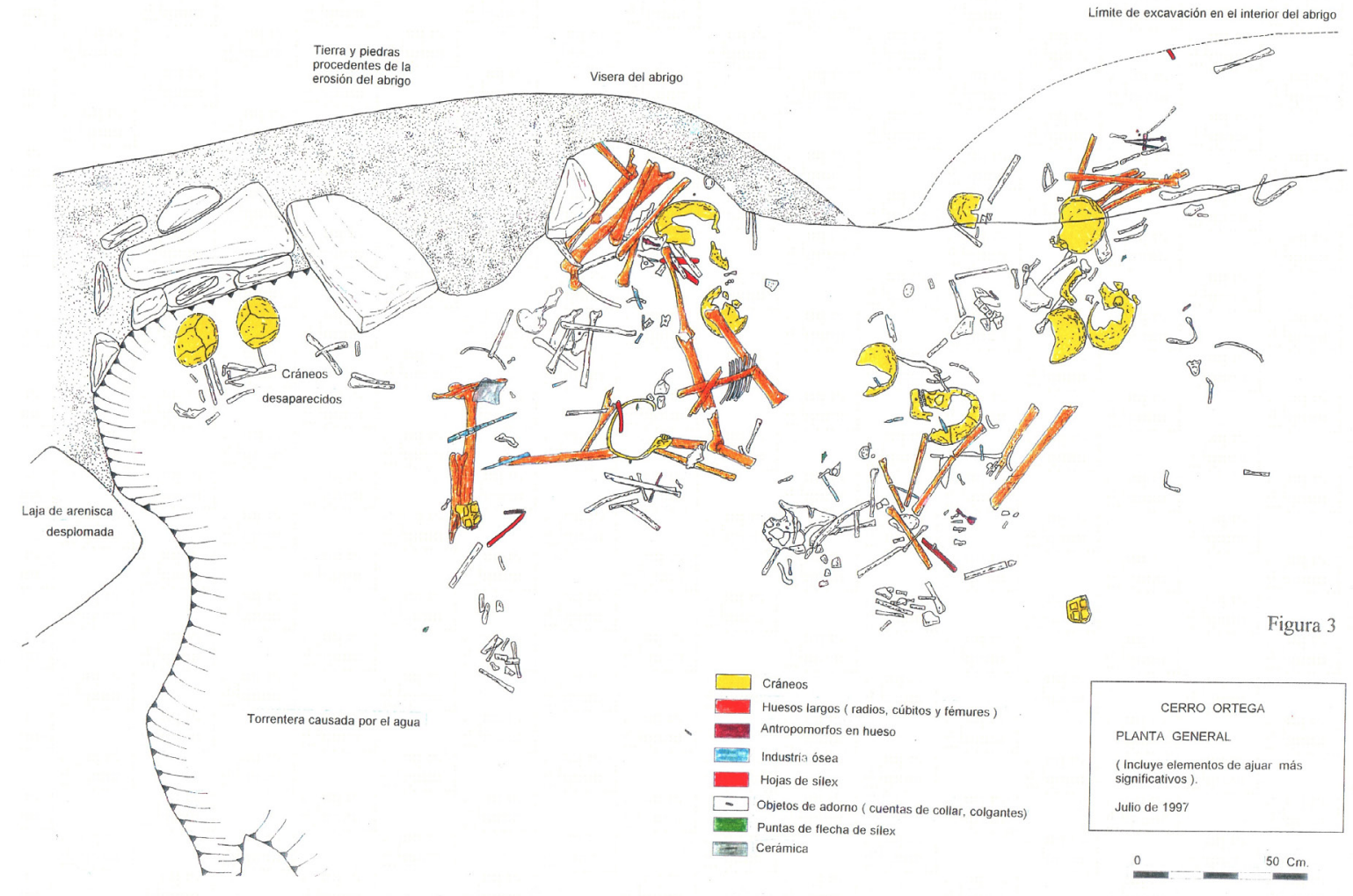

Figura 6. Planta con la disposición de materiales en Cerro Ortega.

en otra (bajo la visera del abrigo). Los estudios antropológicos publicados revelaron el enterramiento en este lugar de un mínimo de 19 individuos, 12 de ellos adultos; su esperanza de vida media era de 40 años. Es interesante señalar que algunos de los huesos humanos largos presentan huellas de descarnamiento (fig. 6).

El hallazgo de aproximadamente 200 fragmentos de huesos de animales -algunos con fracturas en el hueso fresco destinadas probablemente a extraer la médula- junto a algunos carbones puede estar revelando la práctica de ritos de comensalidad cerca del lugar del enterramiento, a decir de sus excavadores. La presencia de fragmentos de cerámica elaborada a mano, entre los cuales destacan los de una ollita de borde entrante y mamelón perforado, puede estar en relación con esas prácticas (Benítez de Lugo 2018). En asociación con los huesos humanos fue encontrado un notable ajuar de hueso trabajado. Cabe destacar la presencia de largas varillas óseas de sección plana o redondeada -algunas con decoración en su extremo proximal-e idolillos antropomorfos esquematizados elaborados en hueso. No menos relevantes son los útiles de sílex amortizados en esta necrópolis: diez puntas de flecha con pedúnculo y aletas $\mathrm{y}$, especialmente, nueve láminas con una longitud máxima de $17 \mathrm{~cm}$, algunas con el filo retocado. Asimismo, fueron recuperados varios colgantes y cuentas, tanto de hueso como minerales: de clinocloro, clinoferrosilita y calcita (Odriozola Lloret et al. 2016). Todos los materiales fueron encontrados juntos acumulados en la misma unidad estratigráfica antes descrita (fig. 7).

\subsection{Motilla del Azuer}

Esta es una de las motillas más grandes y la más extensamente excavada. Fue incluida en este estudio con el fin de explorar el potencial arqueoastronómico de esta clase de sitios (fig. 8).

El Departamento de Prehistoria y Arqueología de la Universidad de Granada comenzó la investigación de la Motilla del Azuer en 1974, en un proceso que puede dividirse en dos períodos. En el primero se sucedieron ocho campañas de excavación y consolidación entre los años 1974 y 1986. Esta fase se inició con la excavación 


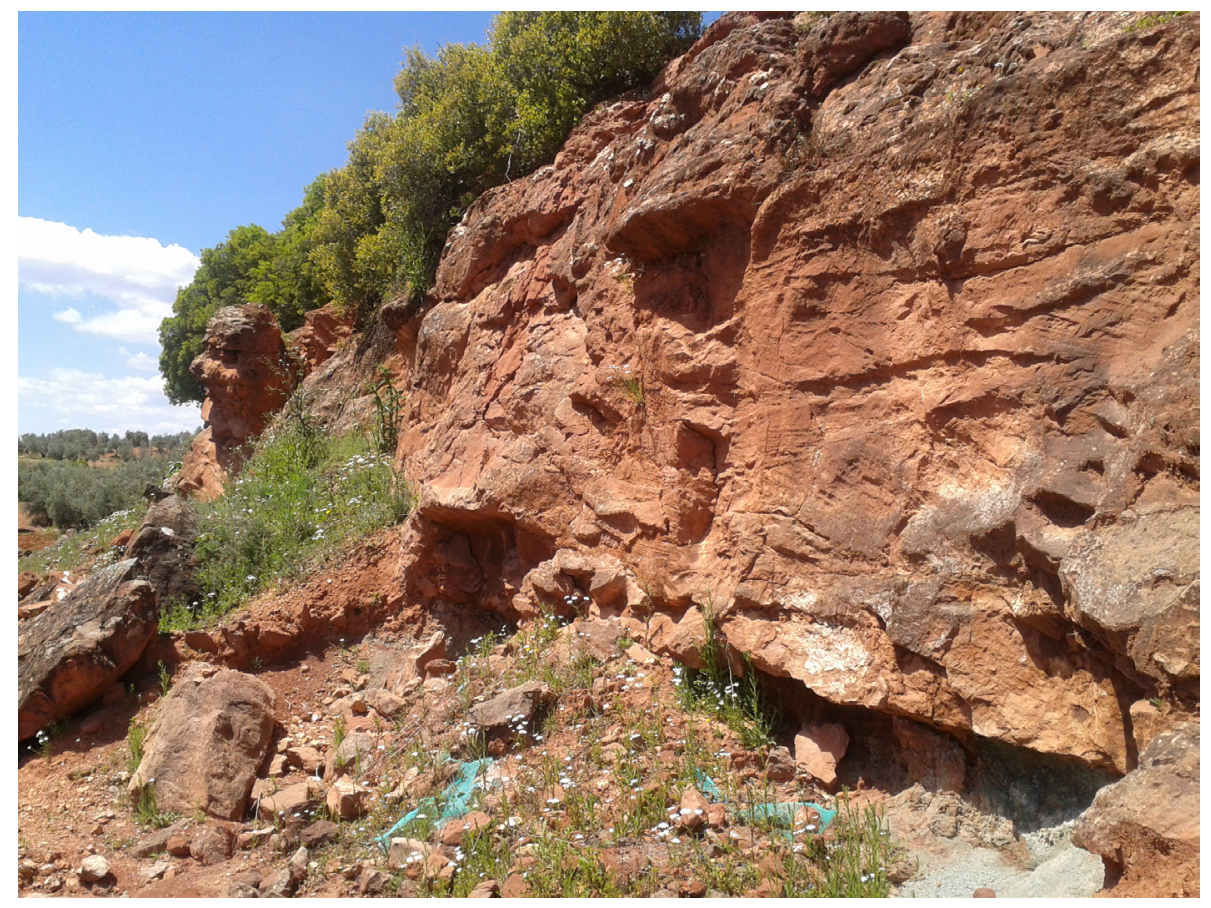

Figura 7. Cerro Ortega. El estrato de marga verdosa deleznable inserta en el paquete de arenisca rojiza, habitual en el entorno, se encuentra asociada a los enterramientos. de dos grandes sondeos estratigráficos dispuestos en forma de cruceta en sentido este-oeste y norte-sur sobre el montículo. Más tarde se amplió la zona excavada, abriendo grandes cortes que pusieron al descubierto parte del área de poblado y la zona del patio oriental. Tras catorce años de abandono, en el año 2000 se reanudaron las investigaciones en una segunda fase de intervenciones promovidas por la Junta de Comunidades de Castilla-La Mancha. En esta segunda fase (evitar repeticiones) se han ido alternando los trabajos de excavación con los de consolidación, restauración y puesta en valor. En la actualidad es el ayuntamiento de Daimiel el que promueve los trabajos en esta motilla, que en los últimos años han sido fundamentalmente de conservación. En el interior de la motilla del Azuer existe un gran pozo que explota el acuífero. Entre otras de sus características cabe citar que no se han descrito recintos de cabañas en su interior, y sí más de un centenar de tumbas. Estas tumbas aparecen en el interior de la motilla. El actual director de los trabajos arqueológicos indica que 'la distribución de la necrópolis coincide con el área espacial del poblado, documentándose incluso bajo el piso de las propias viviendas' (Torres Mas, 2015: 21). Sin embargo, la Universidad de Granada señala que 'al exterior de la fortificación [la motilla] se sitúan las viviendas del poblado' (Aranda Jiménez et al. 2008; Molina González et al. 2005; Nájera Colino et al. 2010 y 2012). En 2013 fue declarada Bien de Interés Cultural (fig. 9).

\subsection{Bocapucheros}

Se trata de un yacimiento arqueológico pendiente de investigación, que cuenta con varias cámaras funerarias y corredores conformando un gran túmulo levantado sobre una cueva natural. Sus arquitecturas y la cerámica que se encuentra en sus alrededores son similares a las de Castillejo del Bonete y permiten adscribir el yacimiento, de forma preliminar, a las Edades del Cobre y del Bronce Inicial. El enclave se construyó sobre un promontorio natural desde el cual hay una gran visibilidad, principalmente hacia el sur y el oeste (fig. 10).

\section{MÉTODO DE TRABAJO}

La Arqueoastronomía es un campo de investigación interdisciplinar que se encarga de estudiar la manera en que las sociedades de épocas pasadas se relacionaron con el cosmos, a partir de los datos arqueológicos, etnográficos e históricos (Cerdeño Serrano et al. 2006). En el caso de culturas tan antiguas como las de la Prehistoria Reciente de la península ibérica, que todavía no habían desarrollado la escritura, su estudio arqueoastronómico puede llevarse a cabo básicamente siguiendo tres métodos de trabajo:

a) Determinando la orientación de estructuras arquitectónicas y explorando su posible relación con los ortos u ocasos de astros de especial interés. 


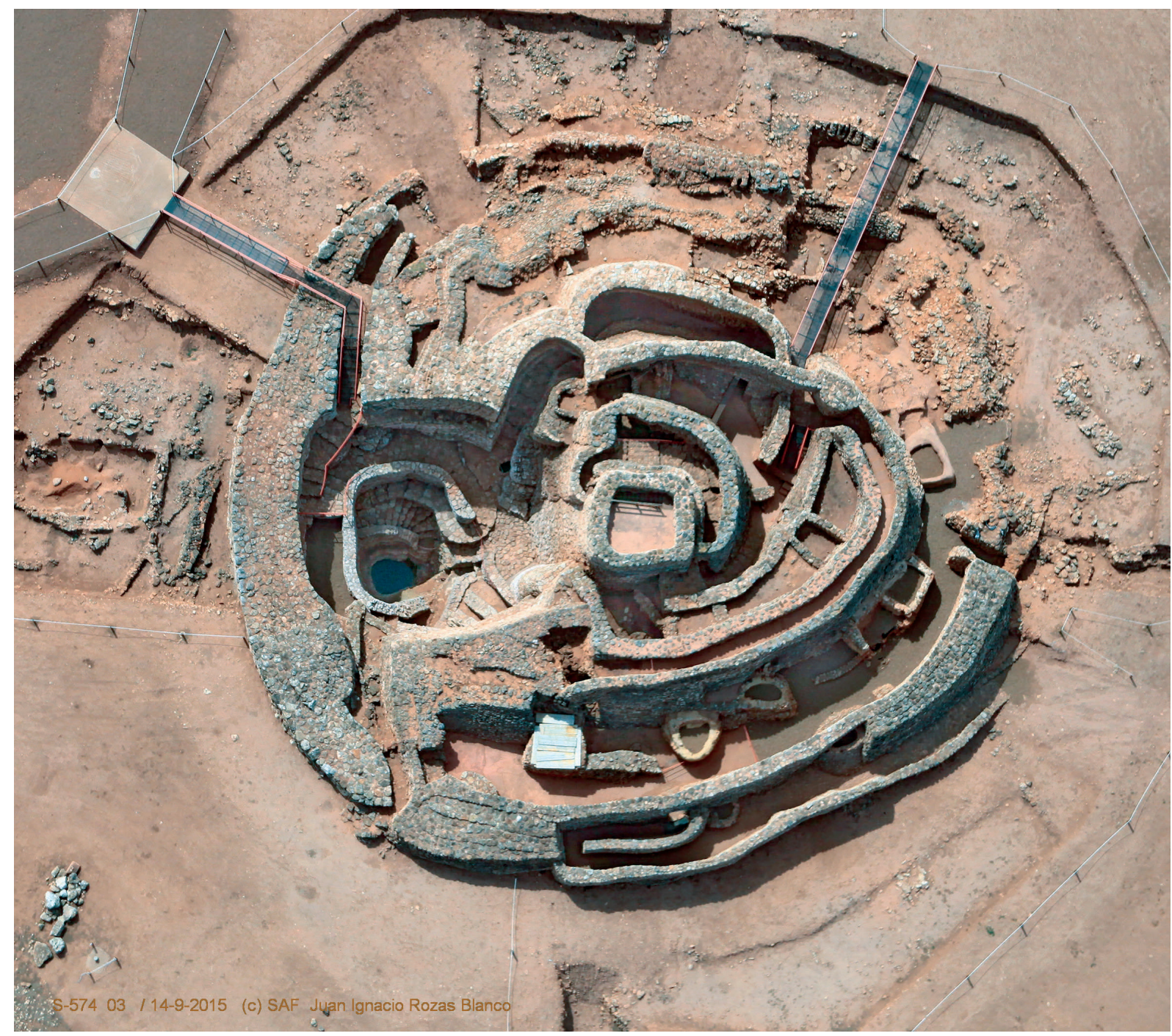

Figura 8. Motilla del Azuer.

b) Estudiando el horizonte que rodea al yacimiento para comprobar la existencia de marcadores de algún evento astronómico.

c) Analizando el contenido astral de las representaciones e imágenes en objetos muebles (utensilios cerámicos, figuras modeladas o talladas) o en paredes de cuevas o abrigos (arte rupestre).

En este trabajo se presentan los resultados de los estudios realizados con los dos primeros de estos métodos. Se analiza la disposición de las estructuras arquitectónicas de cuatro yacimientos arqueológicos localizados en la provincia de Ciudad Real, al sur de la Meseta, y sus respectivos horizontes astronómicos.
El trabajo de campo se llevó a cabo en septiembre de 2014. Los instrumentos utilizados fueron una brújula de precisión, un clinómetro portátil, un teodolito, un dispositivo de posicionamiento global (GPS) y una cámara digital. La metodología utilizada en la recopilación de datos se describe en detalle en Esteban y Moret (2006), que se resume brevemente a continuación.

El GPS se utilizó para obtener las coordenadas geográficas de los sitios, así como para sincronizar las mediciones de la posición del disco solar con el fin de corregir el nivel cero de los ángulos horizontales proporcionados por el teodolito. Se centró el disco solar en el retículo del visor del teodolito varias veces -generalmente tres-durante la visita al sitio. También se utilizó 


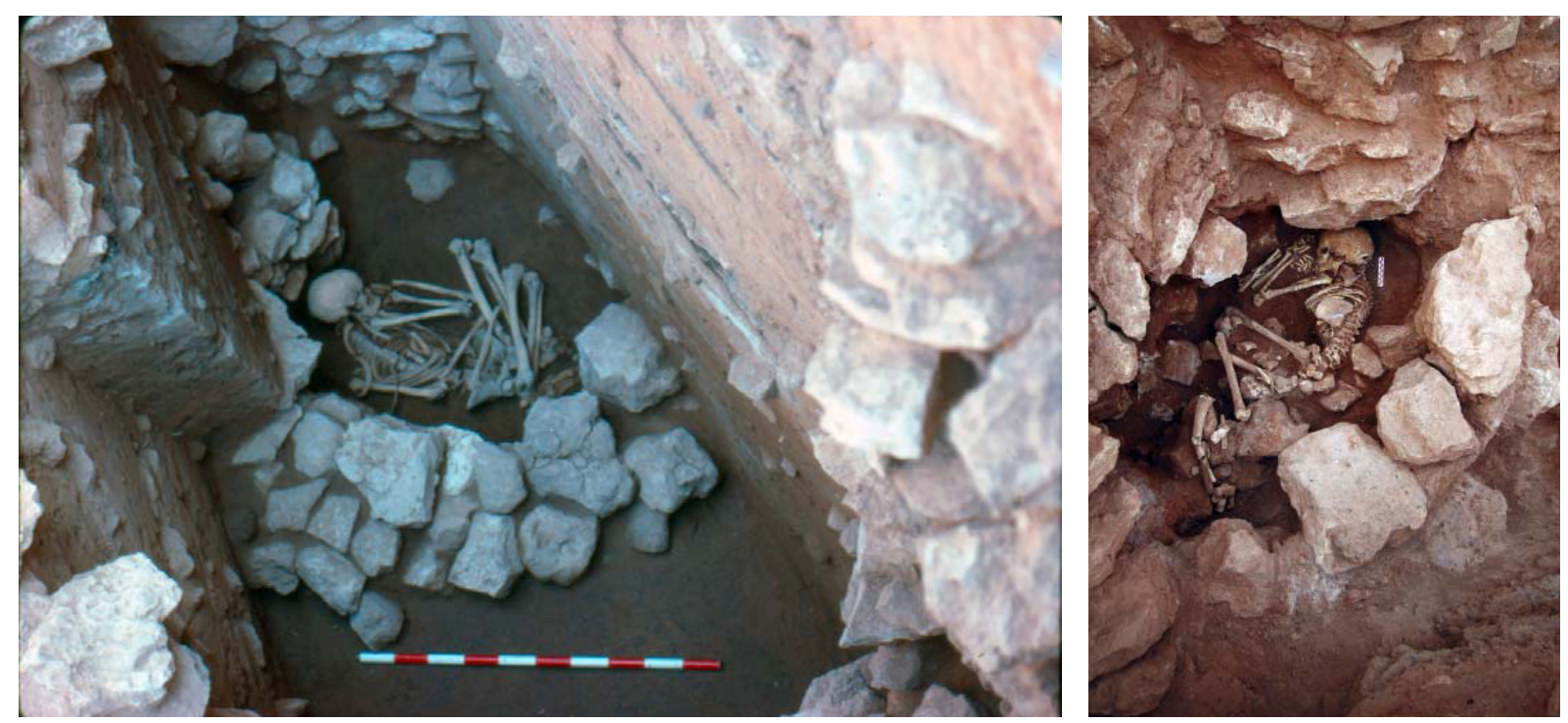

Figura 9. Enterramientos dentro de la motilla del Azuer (Nájera et al. 2012).

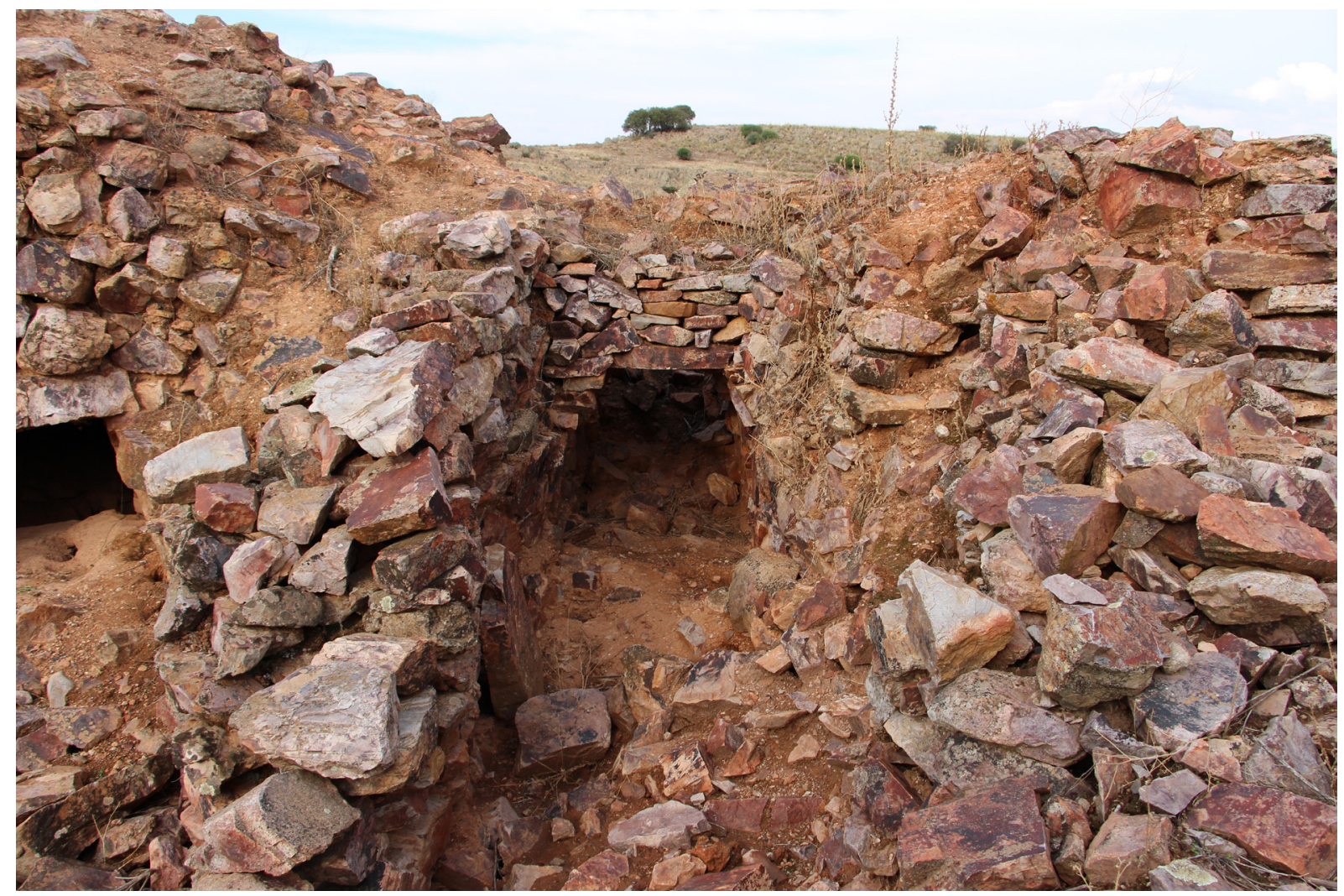

Figura 10. Tumba sur de Bocapucheros. Vista de la cámara y del corredor. 
este instrumento para medir el azimut y la altura de los elementos topográficos más llamativos del horizonte local (picos de montañas, puntos centrales de collados, bordes de escarpaduras), cuya precisión es de $0,05^{\circ}$ en ambas coordenadas. Las medidas de altura fueron corregidas del efecto de la refracción atmosférica cerca del horizonte. La orientación de las estructuras de piedra se midió con una brújula de precisión, cuyas medidas presentan una incertidumbre de alrededor de $1^{\circ}$. La declinación magnética se determinó en cada sitio comparando el ángulo horizontal dado por la brújula con el azimut proporcionado por el teodolito para los diferentes elementos topográficos.

\section{RESULTADOS}

\subsection{Castillejo del Bonete}

Desde este impresionante monumento se divisa una amplia panorámica de casi toda la mitad sur del horizonte, incluidas varias cumbres de las sierras de Alcaraz y del
Segura hacia el sureste. Tras medir la posición de distintos puntos llamativos del horizonte que rodean al yacimiento y, a partir de cálculos sencillos de transformación de coordenadas (ecuación 5 de Esteban y Moret 2006: 171), se determinó su posible relación con los ortos u ocasos de los astros más importantes, detectando un hecho excepcional: la salida del Sol en el solsticio de invierno se debía producir por la montaña más llamativa que se divisa desde el lugar, la Peña del Cambrón, de 1550 m de altura, situada a unos $30 \mathrm{~km}$ de distancia hacia el sureste y que presenta un curioso perfil rectangular, con una cumbre plana y bordes rectos o muy inclinados. El día del solsticio de invierno de 2014, el 22 de diciembre, tuvimos la suerte de observar el amanecer desde el yacimiento con el cielo completamente libre de nubes y niebla. Obtuvimos fotografías y un vídeo con el que resulta posible comprobar que nuestros cálculos eran correctos. Ese día el Sol hizo su aparición por el centro de la Peña del Cambrón, con la montaña actuando como un marcador perfecto del solsticio de invierno (figs. 11 y 12).

En la fig. 11 se muestra la posición actual del disco solar durante el orto del solsticio de invierno (con una

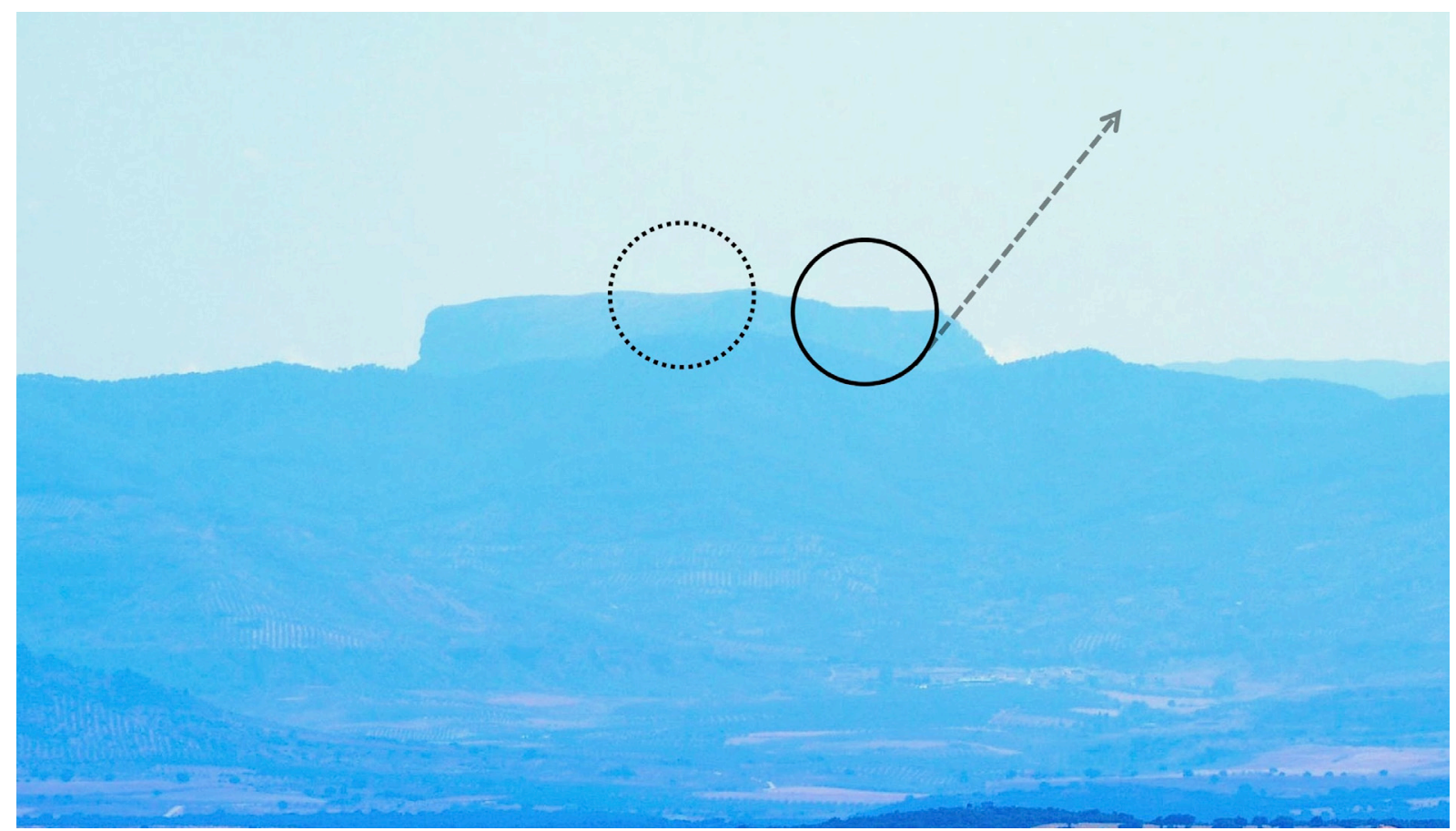

Figura 11. Detalle del horizonte sureste visible desde Castillejo del Bonete. La montaña rectangular del centro es la Peña del Cambrón, en la sierra del Segura. La circunferencia punteada indica el tamaño y la posición del Sol durante el orto en el solsticio de invierno actual (ver también fig. 12). La de línea continua muestra dicha posición alrededor del 2000 a.C., fecha aproximada de construcción del monumento funerario. La flecha de trazo discontinuo representa la trayectoria del borde sur del disco solar durante el orto del solsticio de invierno en aquellas fechas remotas. Nótese que el Sol toca ligeramente el borde sur de la montaña, único momento en que se produciría ese contacto durante el año. 


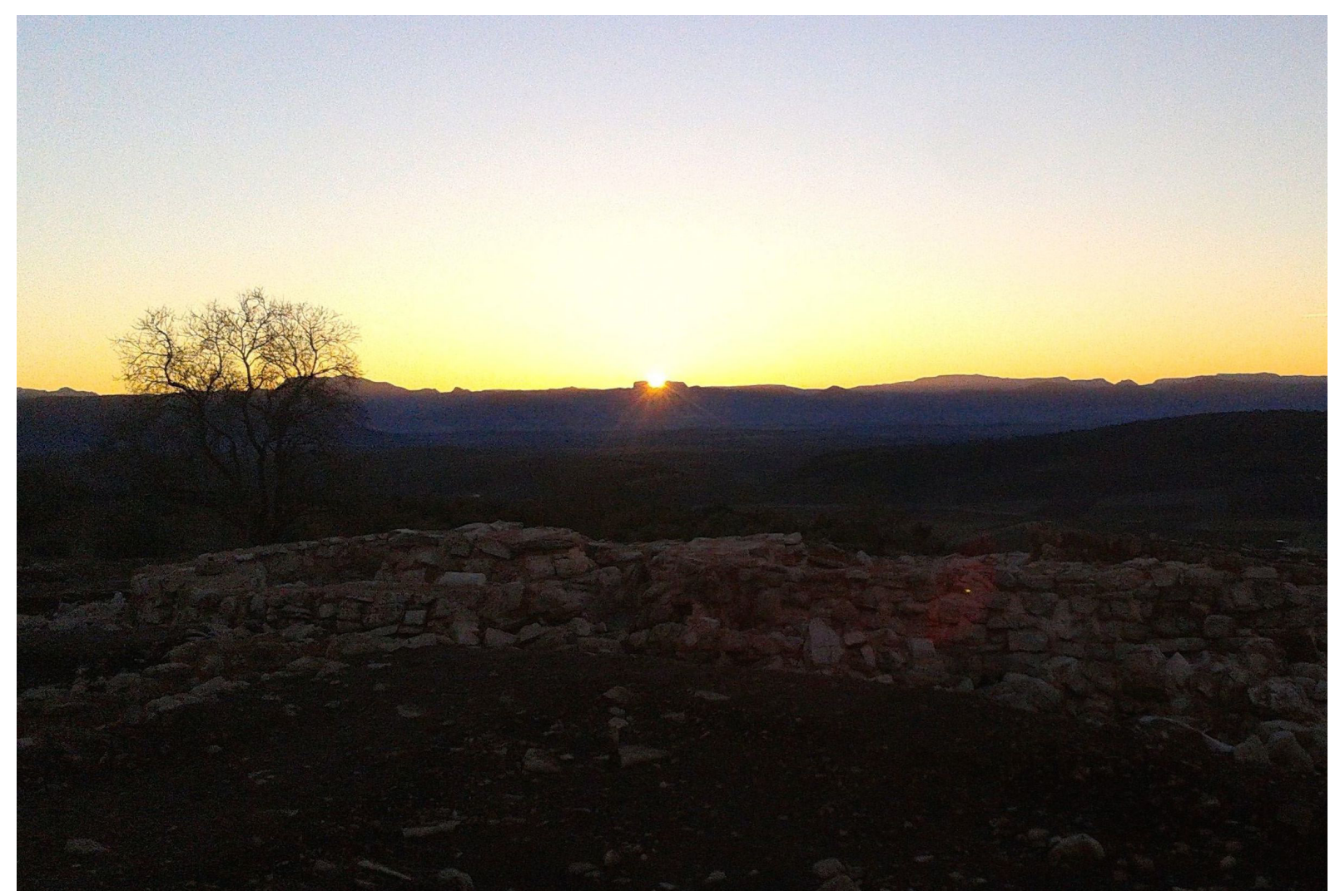

Figura 12. Fotografía del orto solar el día del solsticio de invierno de 2014 (22 de diciembre) desde el monumento solar de Castillejo del Bonete. El disco solar hace su aparición sobre la parte central de la Peña del Cambrón.

declinación $\delta=-23,45^{\circ}$. La declinación es el ángulo que forma la posición de un astro con el ecuador medido a lo largo de uno de los meridianos celestes. Dos astros con declinaciones diferentes describen trayectorias también diferentes sobre la esfera celeste a lo largo de un día) y la que ocupaba en el año 2000 a.C. $(\delta=$ $\left.-23,9^{\circ}\right)$, tal y como lo observarían los constructores de Castillejo del Bonete. Como se aprecia, la posición del astro rey en dicho evento astronómico ha variado muy poco en los últimos 4.000 años, apenas $0,45^{\circ}$, alrededor de un diámetro solar, que es del orden de $0,5^{\circ}$. El solsticio de invierno es uno de los dos puntos extremos en el movimiento anual aparente del Sol sobre la esfera del cielo, corresponde a su posición más meridional y coincide con el momento en que la duración de la noche es más larga con relación al día (fig. 12).

Cálculos realizados para el año 2000 a.C. indican que el intervalo de tiempo desde que el borde sur del Sol toca el extremo norte (izquierdo) de la Peña del Cambrón al amanecer hasta el solsticio de invierno es de unos 18 días. Es decir, el Sol recorre durante 18 días la cumbre plana de dicha montaña desplazándose cada vez más lentamente hacia el sur. Durante los últimos cinco días previos al solsticio, el Sol prácticamente se detendría, moviéndose únicamente $0,1^{\circ}$ (un quinto del disco solar) en dicho periodo y alcanzando a tocar ligeramente el borde sur de la montaña. Los días posteriores al solsticio de invierno el Sol invertiría el sentido de su movimiento sobre la cumbre, abandonándola otros 18 días después. Creemos que un observador experimentado que contara los días transcurridos entre los pasos sucesivos del Sol entre los bordes de la Peña del Cambrón durante algunos pocos años podría haber sido capaz de estimar el día exacto del solsticio de invierno. Por lo tanto, esta llamativa coincidencia pudo haber sido utilizada como marcador calendárico, pero también ritual, del solsticio de invierno.

En Castillejo del Bonete, además del análisis del horizonte, también se obtuvieron medidas de la orientación de sus estructuras arquitectónicas más rectilíneas y de mayor longitud. Los resultados son de gran de interés, pues parecen sugerir una planificación del monumento con posible motivación astronómica. En la fig. 13 se indica la orientación de dichas estructuras. 


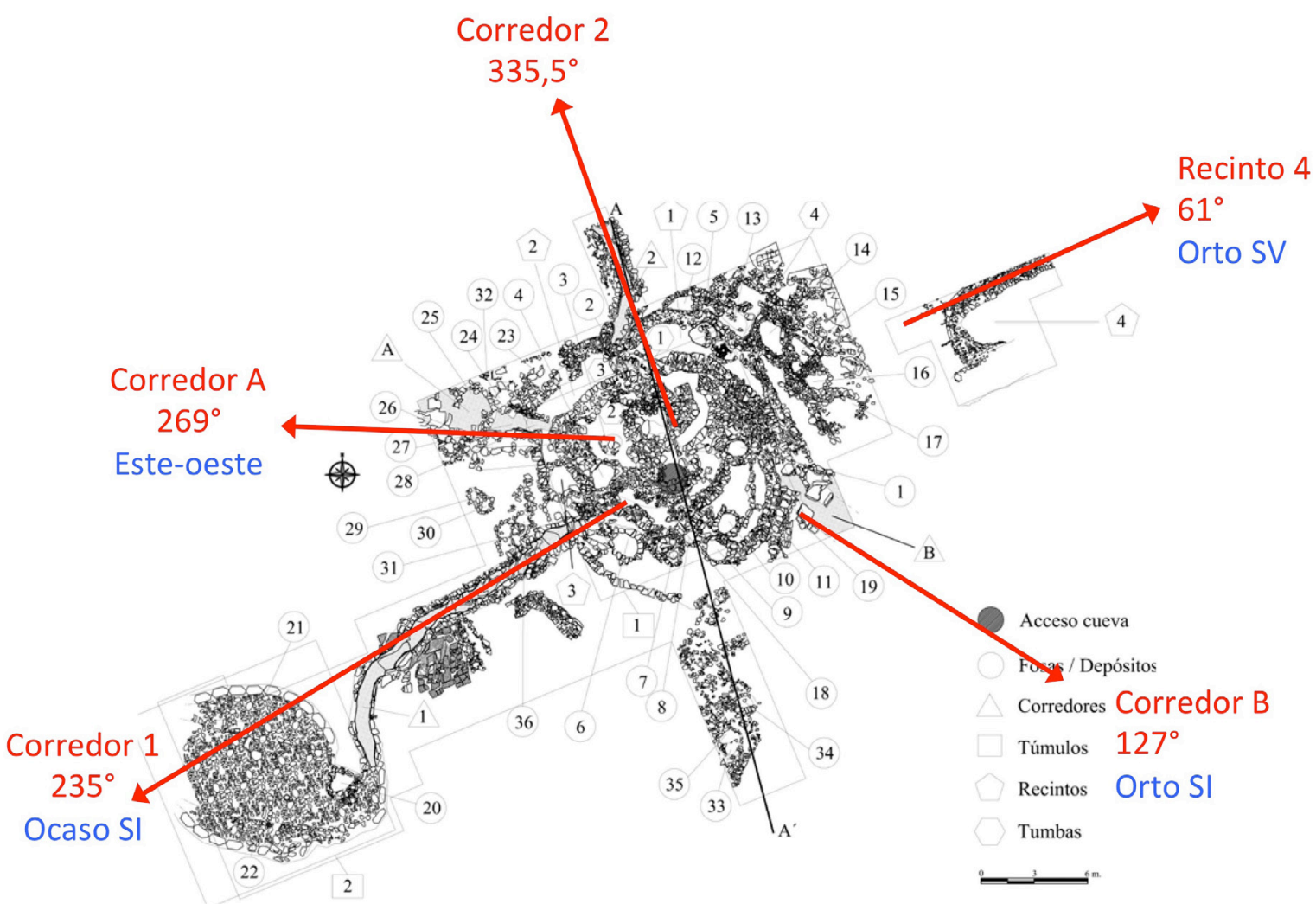

Figura 13. Plano del monumento de Castillejo del Bonete (adaptado de Benítez de Lugo Enrich et al. 2014a: fig. 3) donde hemos indicado la orientación (acimut) de algunas estructuras destacadas y de sus posibles relaciones astronómicas.

Los resultados más destacados son los siguientes:

- El Corredor A (fig. 4) presenta una forma abocinada (sus paredes no son paralelas); la pared sur, la mejor conservada y más larga, muestra una estructura bastante regular y altamente rectilínea y se encuentra orientada exactamente (dentro de una incertidumbre de $1^{\circ}-2^{\circ}$ ) según la línea este-oeste, por lo que podría estar relacionada con el ocaso solar en los equinoccios.

- El Corredor B se encuentra muy deteriorado, pero sus escasos elementos indican una orientación aproximada hacia la peña del Cambrón, el punto del horizonte donde se produce el orto en el solsticio de invierno (ver figs. 11 y 12).

- El Corredor 1, el más largo de los excavados, presenta una larga estructura inicial rectilínea que después se curva enlazando con el Túmulo 2. La parte rectilínea del corredor parecería apuntar (con una incertidumbre de $2^{\circ}-3^{\circ}$ ) hacia el punto del horizonte donde se produce el ocaso solar en el solsticio de invierno (ver fig. 14).
- Los muros norte y sur del Recinto 4 son paralelos y se orientan de una manera similar a la del Corredor 1 (unos $6^{\circ}$ de diferencia). El muro norte apunta con precisión (incertidumbre $1-2^{\circ}$ ) en la dirección del orto solar en el solsticio de verano.

- El Corredor 2 se encuentra orientado en la dirección general del norte, aunque significativamente alejado de él (unos $25^{\circ}$ ). Si variamos el sentido de la orientación del corredor de norte a sur encontramos una curiosa alineación con una montaña picuda situada al sur, El Yelmo, de 1800 m de altura, una de las más altas de la sierra del Segura (fig. 15). Resulta interesante comentar que, en la época de construcción del monumento (2000 a.C.), el orto de las estrellas Rigil Kentaurus ( $\alpha$ Cen) y Acrux ( $\alpha$ Cru) se producía en los alrededores de esa montaña. Estas son las estrellas principales de las constelaciones de Centauro y la Cruz del Sur y son precisamente dos de las más brillantes del hemisferio austral (la cuarta y vigésimo tercera estrellas más brillantes del firmamento), en la actualidad ya no son visibles 


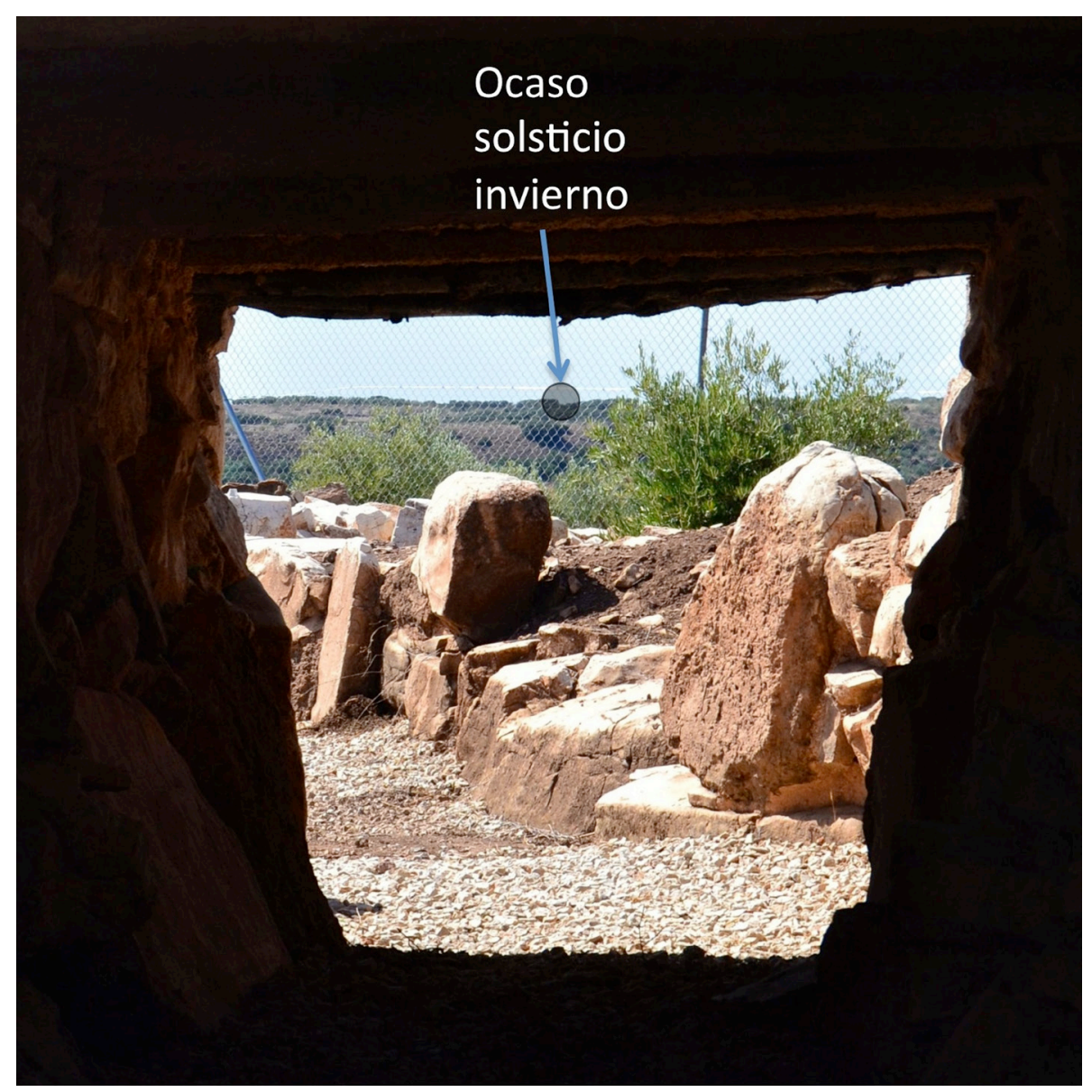

Figura 14. Fotografía obtenida desde el arranque de la zona rectilínea del Corredor 1 y mirando hacia el horizonte suroeste. El círculo representa la posición aproximada y el tamaño del disco solar durante su ocaso en el solsticio de invierno del 2000 a.C. Podemos ver que la parte final del corredor ya no se encuentra alineada con este evento astronómico, torciéndose para enlazar con el Túmulo 2.

desde la latitud del lugar debido a la precesión de los equinoccios (fig. 15). De cualquier manera, teniendo en cuenta que esta orientación no tiene las mismas características que las anteriores (sentido de orientación inverso y con un objetivo estelar, no solar), no debe considerarse con el mismo grado de verosimilitud que los casos anteriores.

Debajo del monumento se encuentra una cueva a la que se accede por el centro del complejo. Una posibilidad pendiente de verificación es que, tal y como se muestra en la fig. 16, dos de las galerías principales pudieran seguir la orientación general de los corredores B y 1, que apuntan aproximadamente hacia el orto y ocaso solar, respectivamente, en el solsticio de invierno. Parece claro que estas orientaciones no tendrían una utilidad práctica, pues la cueva no tiene contacto visual con el exterior, aunque podría tratarse de una orientación simbólica, una repetición de la disposición de las estructuras del monumento en un ambiente subterráneo (fig. 16). Quizás esta coincidencia, junto con la de la existencia del llamativo marcador solsticial sobre el Cambrón, fueron elementos que determinaron la elección del lugar para la construcción del túmulo. Ambos dotarían al conjunto de una gran carga simbólica, de sacralidad, en el caso de que el Sol fuera importante en el mundo religioso y funerario de los constructores del túmulo.

\subsection{Cerro Ortega}

Al no existir estructuras medibles salvo las aberturas (muy derrumbadas y de escasa profundidad) de las tumbas excavadas en la roca, el estudio se limitó a determinar la orientación general de la pared rocosa en la que se encuentran y a realizar el análisis del horizonte (fig. 17).

La dirección perpendicular a la pared rocosa justo en el lugar donde se encuentran las tumbas apunta a un intervalo de acimut comprendido entre $125^{\circ}$ y $128^{\circ}$ (ver fig. 17) que, proyectado sobre el horizonte local y considerando su altura, engloba el punto donde se produce el orto del solsticio de invierno (tanto en el 2000 a.C. como en 


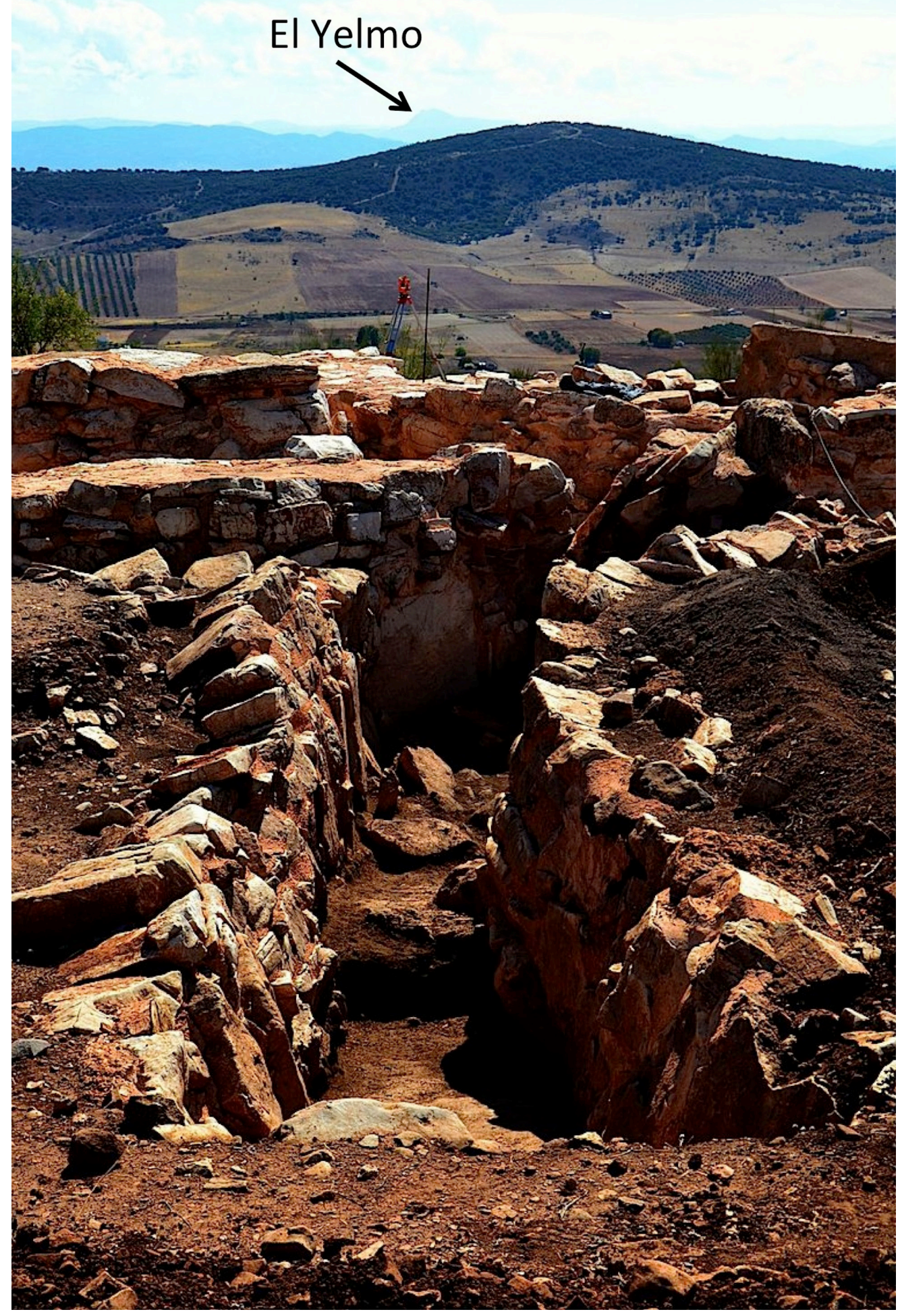

Figura 15. Horizonte sur visto desde el extremo norte del Corredor 2. Este corredor, hacia el sur, parecería estar orientado en la dirección de El Yelmo, cumbre aguda y lejana donde también se producirían los ortos de las estrellas $\alpha$ Cru y $\alpha$ Cen, dos de las más brillantes del hemisferio sur y que podrían haber sido utilizadas como indicadoras de la dirección general del punto cardinal sur. 


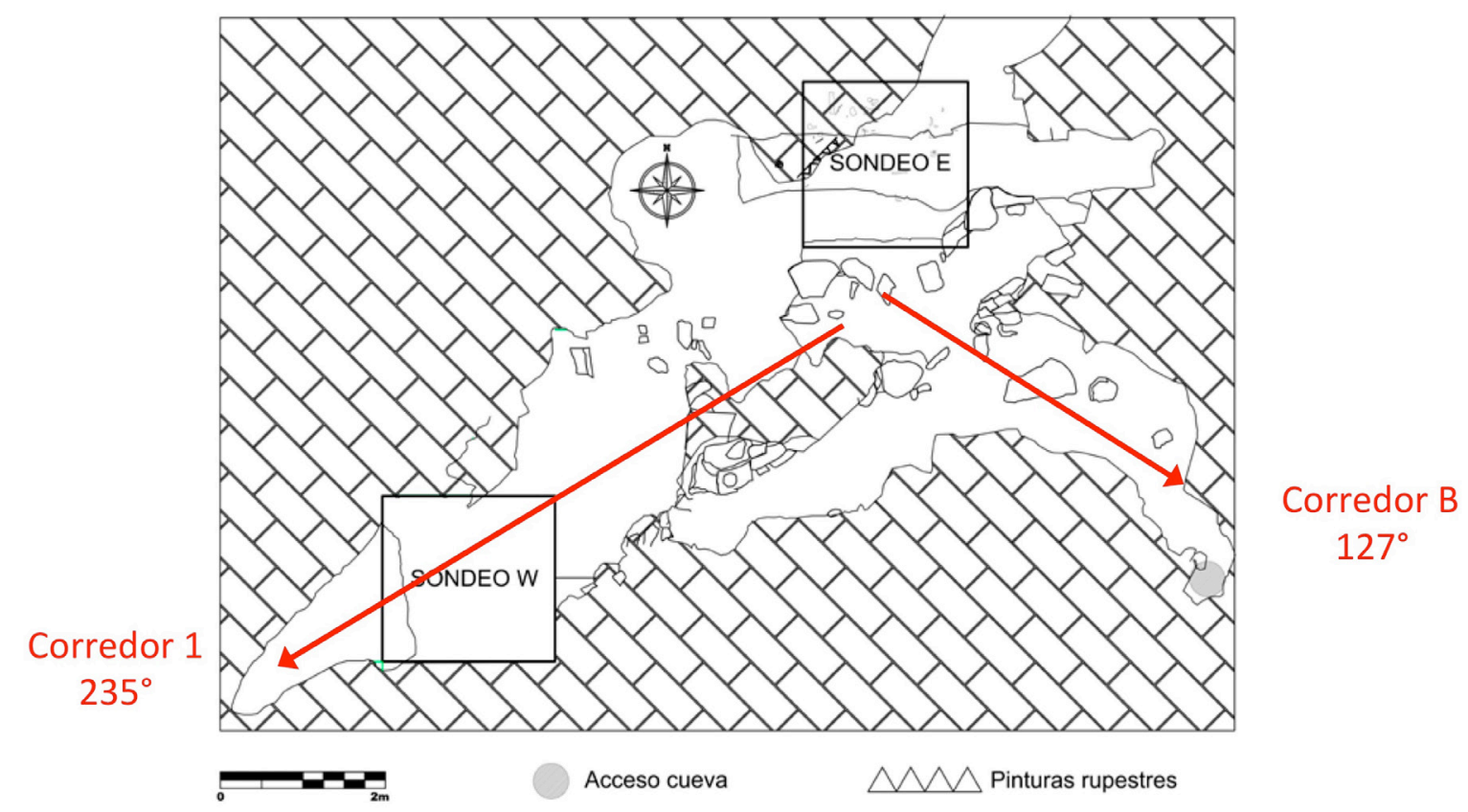

Figura 16. Croquis de la cueva que se extiende bajo el monumento funerario de Castillejo del Bonete (adaptado de Benítez de Lugo Enrich et al. 2014a: fig. 4) donde hemos trasladado la orientación de los corredores 1 y B indicados en la fig. 13. Podemos ver que las galerías que se extienden hacia el sureste y suroeste siguen aproximadamente la orientación de los corredores. Estas dos direcciones apuntan hacia el lugar por donde sale y se pone el sol en el solsticio de invierno. Aunque estos fenómenos son invisibles desde el interior de la cueva, podría tratarse de una orientación simbólica.

la actualidad), que coincide con una de las cumbres de la cercana sierra del Relumbrar, situada en tercer (y último) plano y a unos $4 \mathrm{~km}$ de distancia. Como podemos ver en la fig. 17, la pared rocosa presenta distintas orientaciones a lo largo de toda su extensión, pero parecería que las tumbas se excavaron precisamente en la zona donde su entrada se orienta hacia dicho evento astronómico. Creemos que aunque este hecho, por sí solo, podría considerarse casual, el que coincida con el resultado astronómico principal de Castillejo del Bonete, el orto solar en el solsticio de invierno, sugiere que quizás ambas necrópolis compartan un mismo elemento del ritual funerario relacionado con el ciclo solar. Este hecho implicaría la pervivencia de elementos rituales en el mundo funerario de la zona desde, al menos, finales del Calcolítico hasta la Edad del Bronce.

\subsection{Motilla del Azuer}

Este yacimiento se incluyó en nuestro trabajo arqueoastronómico por ser una de las motillas más representativas y para explorar su posible interés en este sentido.
No se realizaron medidas de orientación de estructuras debido a que todas presentan geometría curvilínea, sin ejes de simetría evidentes que puedan definir direcciones. La visibilidad desde el yacimiento es muy amplia pero pobre en elementos topográficos destacables, al estar situado en una llanura de gran extensión. Las únicas montañas que se divisan en el horizonte son de escasa altura y están, en su mayoría, situadas al sureste (sierras de Alhambra y del Cristo), excepto un pequeño grupo hacia el noroeste (sierra de Malagón). El único resultado de interés astronómico que hemos encontrado en este yacimiento es que el orto del solsticio de invierno se produce sobre una de las mayores alturas que se divisan desde el yacimiento, en la sierra de Alhambra, situada a unos $37 \mathrm{~km}$ (fig. 18). Como en el caso de Cerro Ortega, la relación astronómica que encontramos en la motilla del Azuer no resulta llamativa y también podría ser fruto de la casualidad, pero es consistente al apuntar hacia el mismo evento astronómico que la mayoría de los yacimientos estudiados en el presente capítulo, el orto solar en el solsticio de invierno (fig. 18). 
Figura 17. Fotografía satelital (obtenida de Google Earth) de la zona donde está situada la necrópolis de Cerro Ortega. Las tumbas se encuentran excavadas sobre la base de una pared

rocosa cuya dirección perpendicular apunta a un acimut entre $125^{\circ}$ y $128^{\circ}$, intervalo que comprende el punto donde se produce

el orto del solsticio de invierno. La imagen del recuadro muestra la zona del horizonte hacia donde apunta la entrada de las tumbas y el punto donde se producía el orto solar del solsticio de invierno en el 2000 a.C.
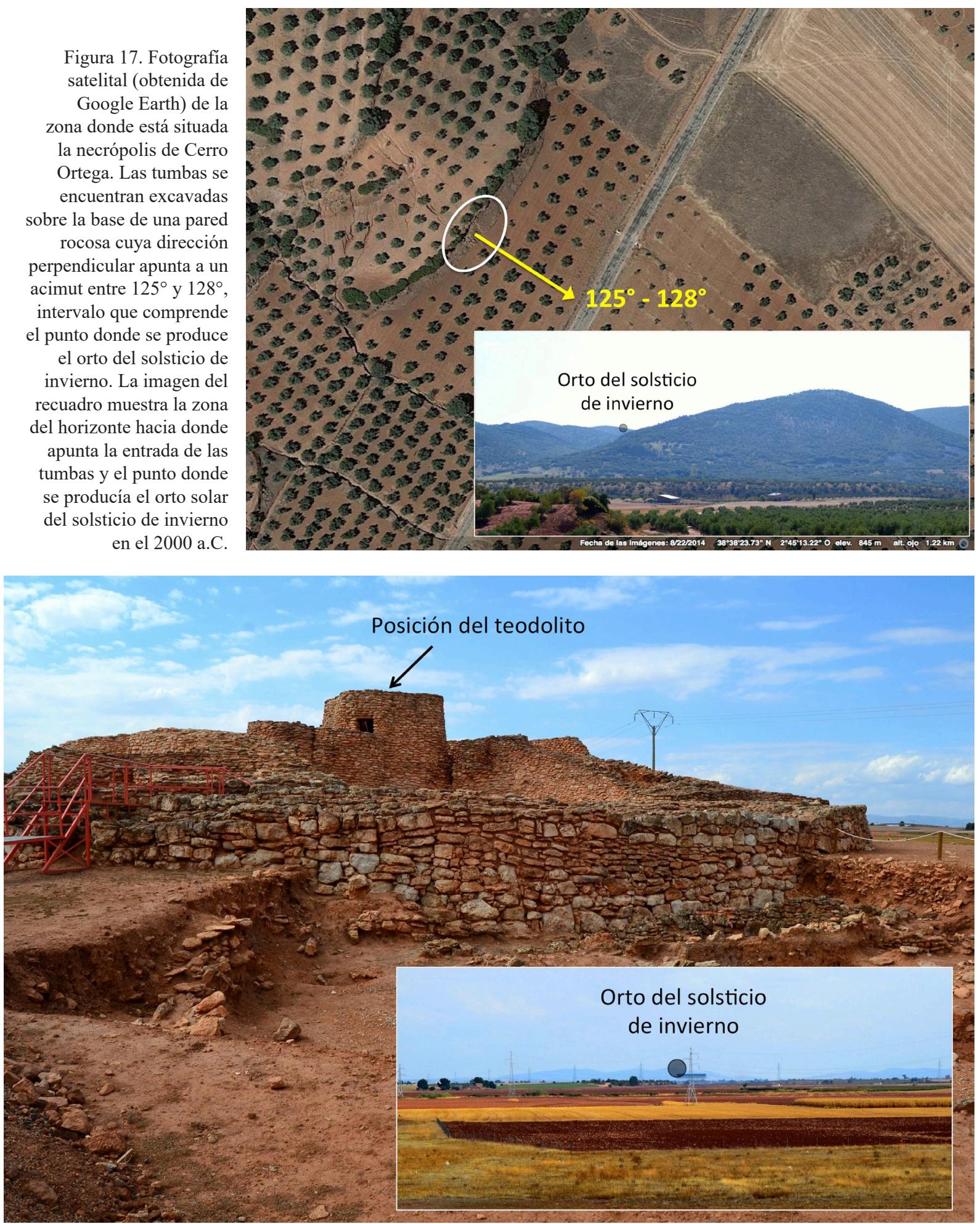

Figura 18. Zona del horizonte donde se producía el orto del solsticio de invierno en el 2000 a.C. desde la torre de la motilla del Azuer. Dicho punto coincide con una de las montañas de mayor altura visibles desde el yacimiento, situada en la sierra de Alhambra, a $37 \mathrm{~km}$ de distancia. El tamaño del disco solar se representa a escala. El recuadro muestra la motilla del Azuer vista desde el este, la flecha indica la posición donde se realizaron las medidas. 


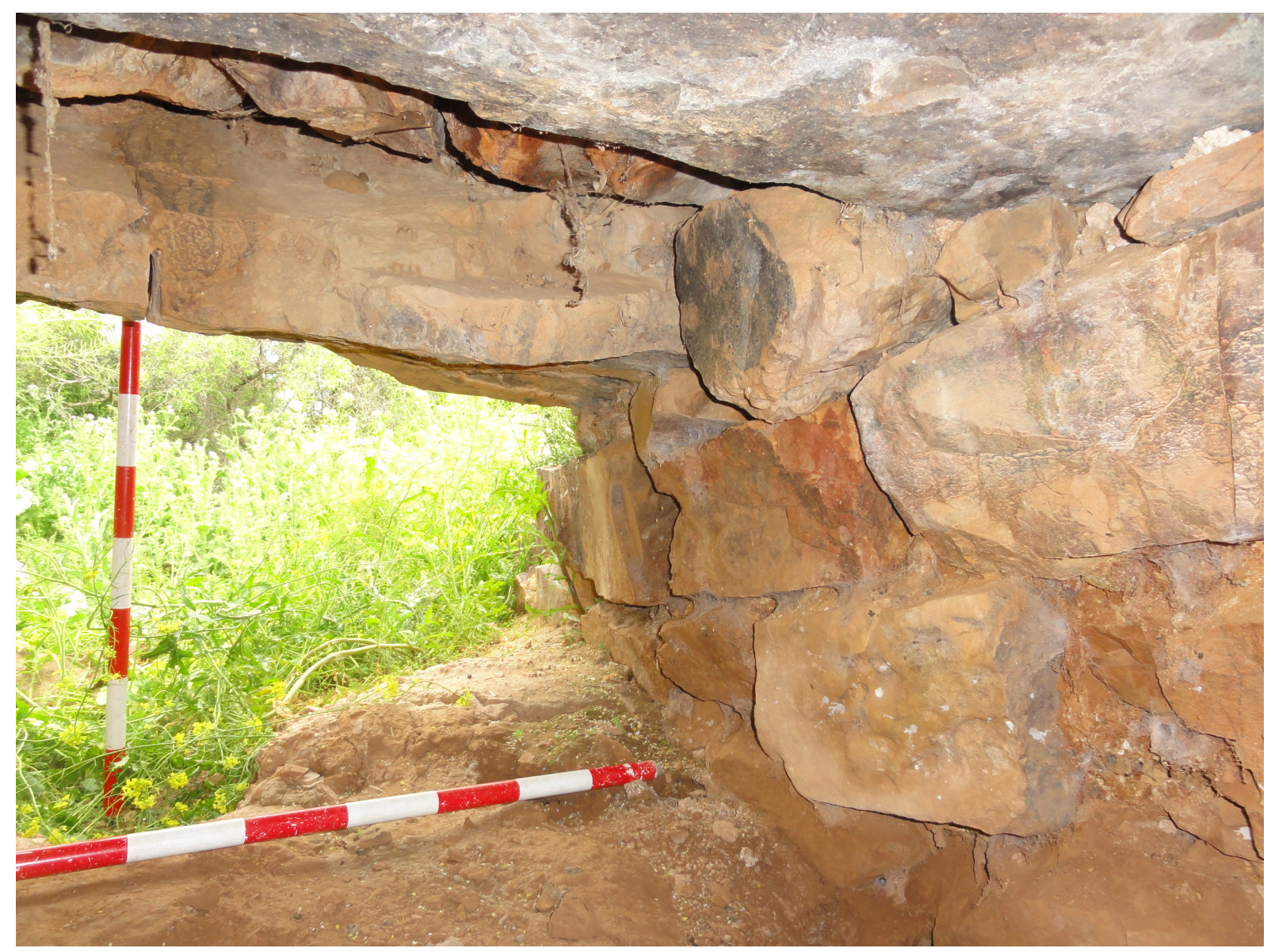

Figura 19. Bocapucheros. Vista desde el interior de una de las cámaras.

\subsection{Bocapucheros}

Este yacimiento consta de una cueva en la ladera occidental del cerro y de una serie de tumbas con cámara y corredor en la parte superior. En esta última zona se midió la orientación de los corredores de tres de las tumbas mejor conservadas. La situada más al sur (fig. 10) presenta un corredor rectilíneo y de gran longitud, mientras que las restantes presentan corredores con diferente orientación, pero mucho más cortos y peor definidos debido a los derrumbes. También se midió la orientación general de la entrada de la cueva subyacente (fig. 19).

Todos los elementos medidos apuntan demasiado al sur para presentar alguna relación hacia ortos u ocasos solares o lunares. Resulta llamativo que el acceso a la cueva (que presenta algunas zonas de muros de piedra) tiene una orientación muy similar a la tumba sur. La parte del horizonte hacia la que apuntan ambos elementos se encuentra ligeramente al norte del paso de SalvatierraCalatrava 'la Nueva'. Mientras la tumba central está orientada exactamente hacia el sur dentro de la incertidumbre de la medida (unos $2^{\circ}$ ), las otras dos parecen estar orientadas a un punto aproximadamente equidistante respecto al meridiano, la tumba norte hacia oriente y la sur a poniente. El único objetivo astronómico de interés que tiene su orto y ocaso simultáneamente en las direcciones definidas por las tumbas norte y sur es la constelación de la Cruz de Sur (con la que ya encontramos una posible relación en el caso del Corredor 2 de Castillejo del Bonete). Las estrellas más brillantes de dicho grupo estelar Gacrux, Mimosa y Acrux ( $\gamma, \beta$, y $\alpha$ Cru) estaban, alrededor del año 2000 a.C., en una posición compatible con dichas orientaciones. Resumiendo, la tumba norte podría estar orientada hacia el orto de la Cruz del Sur, la central a su culminación sobre el meridiano (culminación de un astro o de una constelación corresponde al momento en que pasa por el meridiano del lugar, la línea imaginaria que pasa por el cénit y los polos, y es cuando alcanza la máxima altura respecto al horizonte) y la tumba sur (y la entrada de la cueva) a su ocaso. 


\section{DISCUSIÓN}

A lo largo de toda la Prehistoria Reciente se rastrean al sur de la Meseta evidencias rituales vinculadas a los astros; desde el Neolítico hasta la Edad del Bronce, desde túmulos hasta estaciones de arte rupestre, motillas o tumbas.

Los rituales vinculados a los astros eran ya conocidos en otros lugares del mundo, pero resulta una novedad de calado detectarlos al sur de la Meseta. Las evidencias presentadas suponen un avance en el conocimiento de los aspectos de las sociedades prehistóricas del interior peninsular.

Algunos estudios paleopalinológicos sobre la Meseta de la península ibérica indican que a partir de la segunda mitad del III milenio cal BC se vivió un prolongado periodo especialmente seco y árido (López Sáez et al. 2014). La construcción de las motillas en La Mancha coincide con ese evento climático abrupto, caracterizado por su extrema aridez y conocido como Evento 4.2 ka cal BP, o Bond Event 3 (Benítez de Lugo Enrich y Mejías Moreno 2015, 2016 y 2017). El repentino cambio climático, relacionado a nivel mundial con el ocaso de diversas culturas, coincide en La Mancha, como ya se ha dicho, con la construcción de las motillas, pero también con la utilización de los túmulos de Castillejo del Bonete. Se trata de un momento de creciente complejidad social en las primeras comunidades agrarias, en el camino hacia la jerarquización y la creación de una sociedad compleja. Los cambios adaptativos y estratégicos hicieron posible la continuidad del poblamiento en La Mancha durante la transición entre el III y II milenio cal a.C., en un momento de estrés ambiental, a partir de una reorganización de la explotación de los recursos, y con las motillas como novedosa y singular solución ante la mencionada crisis ambiental. Muy probablemente, el mayor impulso para la construcción de las motillas es coincidente con los momentos de mayor sequía y aridez, pudiendo situarse el colapso de esta cultura alrededor de $1400 \mathrm{cal} \mathrm{BC}$, tras el progresivo regreso y consolidación de condiciones ambientales más húmedas y cálidas.

El carácter simbólico de las motillas se encuentra insuficientemente estudiado por el momento. El avance en este aspecto podría llegar a partir de yacimientos como Castillejo del Bonete, situado también al sur de la Meseta y que presenta una forma, una cultura material y una datación similares a las de las motillas conocidas hasta el momento. La presencia en las motillas de elementos arquitectónicos y materiales como los que se encuentran en los túmulos (corredores, tumbas, depósitos siliformes, accesos al subsuelo mediante galerías o pozos, etc.) debe mover a la reflexión sobre la habitual caracterización de estas estructuras como poblados fortificados. El descubrimiento en la cultura del Bronce de La Mancha de monumentos funerarios complejos, constituidos por grandes túmulos construidos en clave astronómica, con una forma externa similar, al menos en la actualidad, a los lugares considerados de habitación (morras y motillas) pone en primer plano la relación entre estos lugares. La existencia en estos túmulos de ofrendas rituales depositadas en estructuras siliformes exige extremar la cautela a la hora de asociar cualquier estructura de esta clase con una estricta funcionalidad de almacenamiento, especialmente cuando esas estructuras se encuentran asociadas a tumbas. El descubrimiento dentro del complejo tumular de Castillejo del Bonete de depósitos con centenares de objetos de diferente clase en hoyos con apariencia de silos, construidos con toda seguridad con fines rituales, exige reconsiderar que, en aquel tiempo, las edificaciones en las que aparecen silos, o cereal, sean necesariamente poblados. Por ejemplo, construcciones identificadas como silos cubiertas de piedras y tierra que fueron consideradas derrumbes, y con muertos alrededor, han sido descritas en la motilla del Azuer o en La Encantada. La clasificación en el Bronce de La Mancha de numerosos 'poblados' con forma tumular emplazados en lugares con gran visibilidad requiere, tras hallazgos como los que se vienen presentando, una revisión del papel que desempeñaron esos enclaves arqueológicos (Benítez de Lugo Enrich et al. 2014-2015: 200).

Los depósitos rituales y los ritos de comensalidad han sido certificados durante la Prehistoria Reciente en momentos y lugares dotados de una elevada carga simbólica. Los muertos y las construcciones tumulares sirvieron en la Prehistoria Reciente para legitimar la pertenencia de un territorio a un grupo. Es posible que un relato religioso vinculado con el ciclo solsticial muerteresurrección del Sol fuera utilizado como recurso simbólico en la gestión de las relaciones poder y para el control de un recurso tan estratégico para la subsistencia en La Mancha como fue el agua. Las motillas fueron una red de enclaves dotados de una alta carga simbólica, como lo demuestran los muertos allí enterrados y el acceso al agua salvadora procedente de un inframundo subterráneo, que permitió sobrevivir a una comunidad resiliente durante un largo periodo de estrés ambiental por déficit hídrico. Allá donde no es posible la construcción de motillas existen monumentos como Castillejo del Bonete, en donde es posible desvelar a través de la cultura material un discurso simbólico que se muestra común. En este yacimiento se ha encontrado cerámica con decoración 

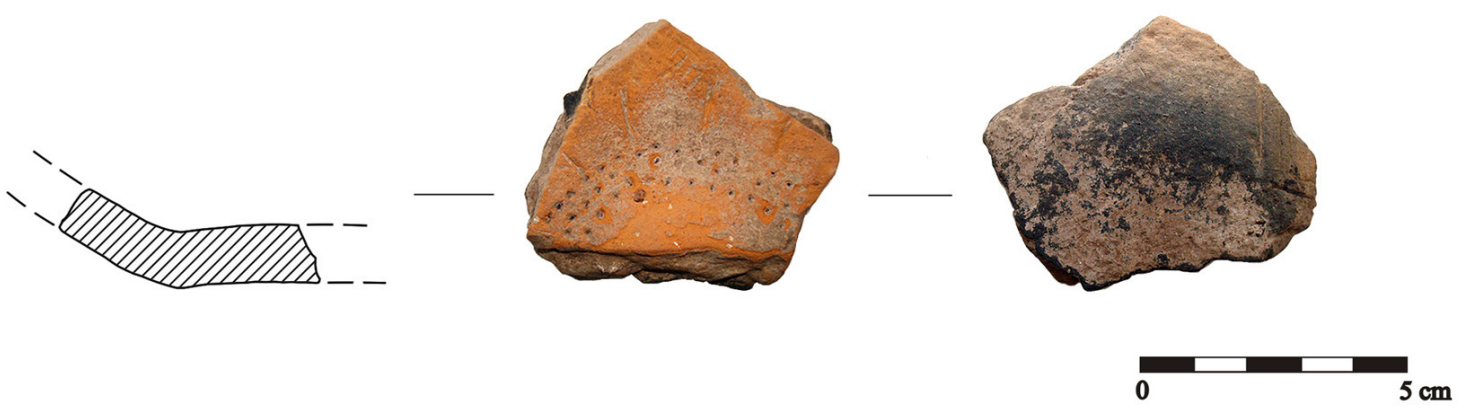

Figura 20. Soliforme inciso sobre fondo cerámico encontrado en Castillejo del Bonete.

soliforme esquemática incisa, que no puede dejar de ser relacionada con las orientaciones solsticiales que presentan varias de las estructuras arquitectónicas del yacimiento (ibídem: 135) (fig. 20).

Se han descrito fuegos rituales en relación a otros enterramientos prehistóricos múltiples en La Mancha (Gutiérrez Sáez et al. 2000 y 2002). En Castillejo del Bonete se han documentado en el interior de una cueva monumentalizada y utilizada con fines rituales, además de sobre tumbas. En este caso se arrojó a la hoguera una flecha con punta del tipo Palmela (Benítez de Lugo Enrich et al. 2015a: 125) (fig. 21).

La relación entre el mundo funerario, el inframundo y el renacimiento de los muertos en la Prehistoria Reciente de la zona que nos ocupa en este trabajo parece reflejada de forma simbólica en el enterramiento individual neolítico localizado en Villamayor de Calatrava (Ciudad Real), posiblemente cercano a un poblado de la misma época. Este hallazgo dejó al descubierto un inhumado enterrado en decúbito lateral izquierdo, flexionado dentro de una fosa en forma de pera que tenía una profundidad aproximada de $2 \mathrm{~m}$ y estaba rellena de tierra gris oscura, diferente de la del entorno. El cadáver fue depositado sobre un lecho de tierra gris más oscura que contenía piedrecitas calizas, algunos restos de fauna, fragmentos de recipientes cerámicos con decoración incisa e impresa y algunos útiles líticos tallados y pulidos. Una cuenta discoidal y una pequeña lúnula, ambas elaboradas a partir de conchas de moluscos marinos, formaban parte del adorno personal de la persona allí enterrada. Los investigadores de este hallazgo llamaron la atención sobre la semejanza entre la forma del enterramiento y la de un feto dentro del útero materno. También subrayaron la dificultad para colocar al difunto en el fondo de la fosa abierta: hubiera sido mucho más sencillo colocar al muerto en decúbito supino en una fosa rectangular más somera, en vez de en el fondo de una profunda estructura de boca estrecha (Rojas Rodríguez-Malo y Villa González 2000: 12) (fig. 22). De lo expuesto interesa al caso que nos ocupa que estos investigadores interpretaron el rito documentado en el marco de las creencias acerca del renacimiento de los muertos, generalizadas a lo largo de la Prehistoria Reciente en el seno de las primeras comunidades agrarias.

Recientemente el catedrático de la Universidad Autónoma de Madrid José Antonio González indicaba, al analizar los últimos estudios interdisciplinares sobre el Bronce de La Mancha, que "Los rituales en el Bronce de La Mancha no eran de desarrollo limitado (más bien parece suceder todo lo contrario); lo que era limitado era su conocimiento hasta el descubrimiento de Castillejo del Bonete' (González Martín 2016: 226). Nuestros resultados inciden claramente en una ritualidad compleja en el Bronce de La Mancha, donde los elementos astrales tenían una especial relevancia.

Antes de nuestro estudio arqueoastronómico, los únicos indicios de la presencia de elementos astrales en la simbología de la época y zona geográfica que nos ocupa provienen de algunas representaciones pictóricas. Al sur de La Mancha existen numerosos abrigos con arte rupestre esquemático. Es comúnmente aceptado que este tipo de grafías prehistóricas deben ser relacionadas con las primeras comunidades metalúrgicas de las edades del Cobre y del Bronce inicial (Fernández Rodríguez 2003: 277). El significado que tuvieron este tipo de manifestaciones aún no ha sido explicado satisfactoriamente, aunque algunos de ellos presentan representaciones que pueden interpretarse como astrales. Motivos soliformes han sido descritos, por ejemplo, en los paneles 3 y 4 de Peña Escrita o en La Golondrina (Fuencaliente, Ciudad Real) (Caballero Klink 1983, vol. I: 223 y vol. II: planos 81, 82 y 89; Fernández 


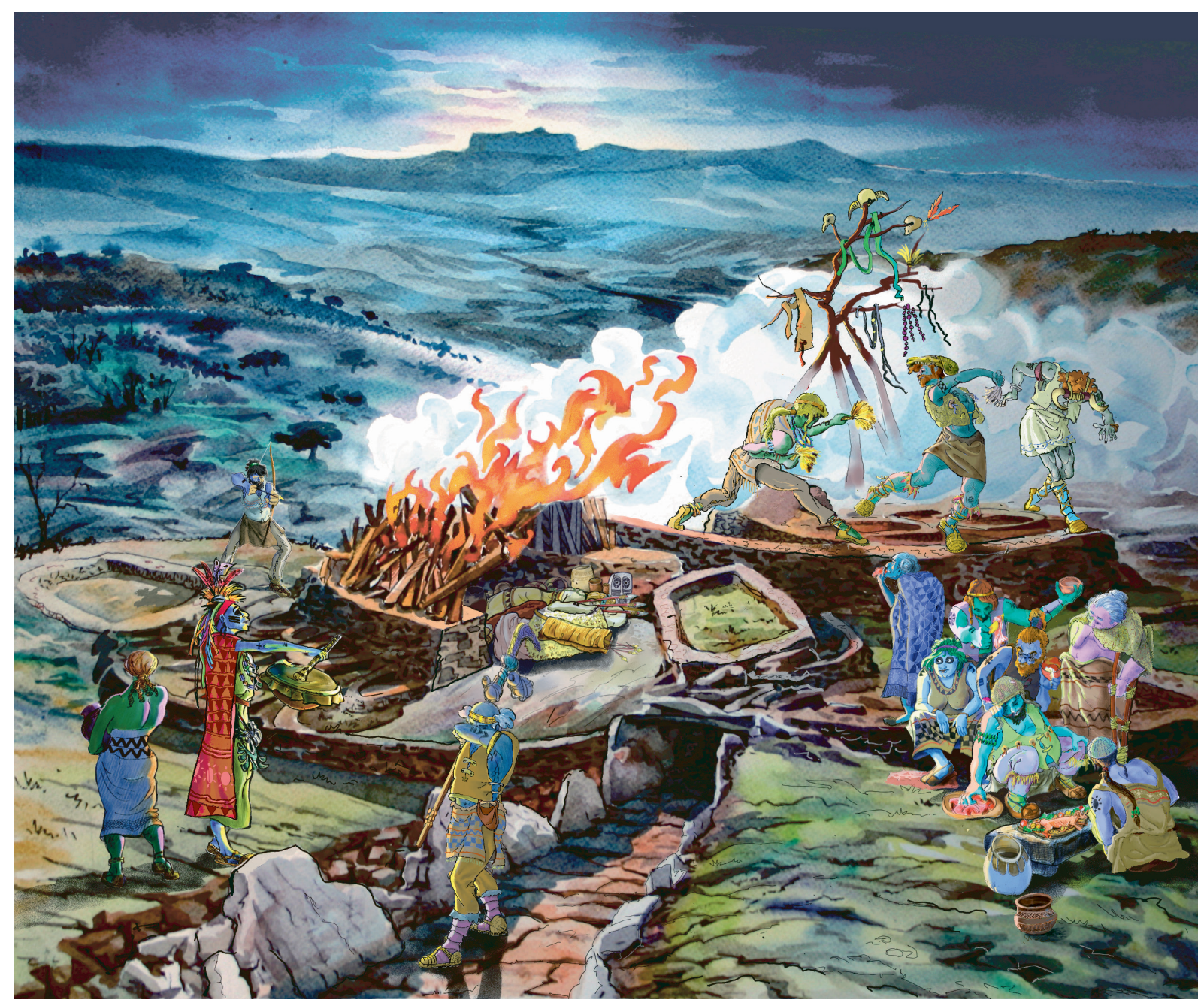

Figura 21. Recreación de rito en Castillejo del Bonete durante el amanecer en el solsticio de invierno. Una flecha es arrojada a un fuego ritual que se ha encendido sobre una tumba. La comunidad come y bebe en el lugar.

Rodríguez 2003: 193) o Callejones de Riofrío II (Mestanza, Ciudad Real) (ibidem: 218). La realización de estudios arqueoastronómicos sobre estos abrigos es una tarea pendiente (fig. 23).

La península ibérica es rica en monumentos funerarios megalíticos de distinta tipología que se construyeron entre el VI y el III milenios a.C. Disponemos de medidas precisas de la orientación de los corredores o ejes de simetría de más de mil de estas estructuras, aunque no en la zona de La Mancha (Hoskin 2001; González García 2009). Los resultados, especialmente los referidos al área de Andalucía, Extremadura y Portugal, indican que los monumentos apuntan sistemáticamente a un rango de acimuts relativamente estrecho del horizonte oriental, indicando un patrón de orientación no aleatorio.
La motivación de esta tradición, extendida en una amplia área geográfica y mantenida durante miles de años, a buen seguro fue poderosa y perdurable. No pudo basarse en un referente puramente local como, por ejemplo, la dirección de los vientos o un elemento topográfico destacado del horizonte, pues se repite en zonas muy alejadas, sino en un elemento del contexto común para todos los grupos humanos que construyeron esos monumentos. Una de las hipótesis más verosímiles es que los objetivos de las orientaciones sean los puntos del horizonte donde se producen los ortos u ocasos de algún cuerpo celeste (Ruggles 1999: 1-11). Los argumentos son sencillos, la esfera celeste es algo compartido por todas las sociedades humanas y la posición de los cuerpos celestes ha sido, en todas las épocas de las que tenemos noticias, 


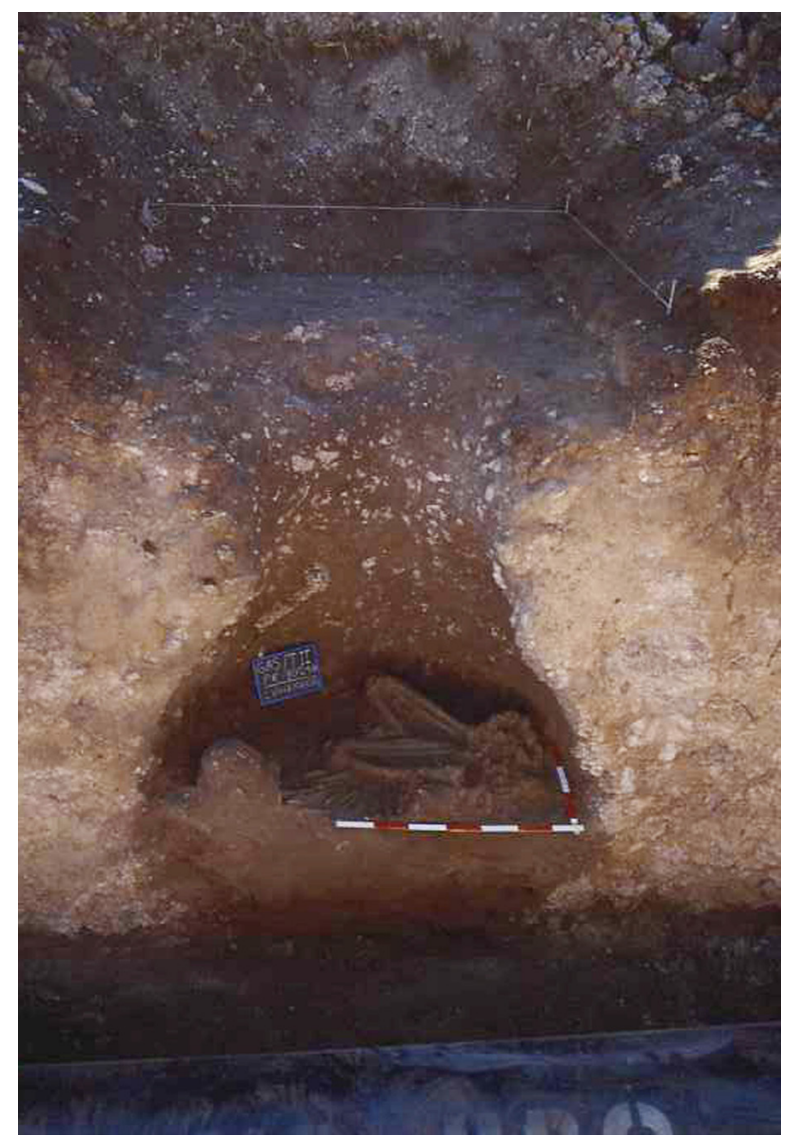

Figura 22. Tumba neolítica de Villamayor de Calatrava. Fotografía: Juan Manuel Rojas Rodríguez-Malo y Ramón Villa González.

un elemento esencial para la determinación de direcciones y para el cómputo del tiempo. Por otra parte, son muchas las culturas del pasado para las que los astros fueron elementos centrales en sus creencias religiosas y funerarias. Aplicando razonamientos de este tipo, diversos autores (como Hoskin 2001: 93) han propuesto que el patrón de orientación que encontramos en los monumentos megalíticos del sur y oeste peninsular podría obedecer a su apuntado deliberado hacia los lugares del horizonte donde se produce la salida del Sol o de la Luna, a lo largo del año o en ciertos momentos de especial significación calendárica o ritual. Como vemos, nuestros resultados sobre la orientación de algunas estructuras de Castillejo del Bonete son compatibles con los encontrados para muchos monumentos funerarios megalíticos peninsulares y los hace partícipes, al menos en cierta medida, de esta tradición milenaria.

Sin embargo, hay algo en Castillejo del Bonete que lo hace singular respecto al resto de monumentos megalíticos peninsulares conocidos y es la presencia de un claro marcador solar. En el caso de dólmenes, tenemos varios ejemplos en que los corredores parecen apuntar hacia montañas prominentes del paisaje, como en Los Millares (Almería) y en el enorme dolmen de Menga en Antequera (Málaga) (Belmonte y Hoskin 2002: 72, 78). De estos, solo en el caso de Menga la orientación podría tener alguna relación astronómica, específicamente con el orto lunar en el lunasticio mayor norte (J.A. Belmonte, comunicación privada), la posición más septentrional que alcanza la Luna. Hasta donde sabemos, el único marcador astronómico claro registrado en un monumento megalítico ibérico se encuentra en el crómlech de Oyanleku (Guipúzcoa), cuyo eje principal apunta hacia el llamativo perfil de Peña de Aya, donde se producía el orto de la Luna en el lunasticio mayor norte en el 3000 a.C. (Belmonte y Hoskin 2002: 45-46). Nuestros resultados indican que el llamativo orto solar solsticial sobre la Peña del Cambrón que observamos en Castillejo del Bonete constituye el primer marcador solar confirmado en el horizonte que rodea un monumento funerario megalítico en la penínsulai Ibérica.

La ausencia de marcadores astronómicos en los monumentos megalíticos españoles contrasta con lo que se encuentra en los yacimientos de las islas británicas, donde muchos círculos de piedra y conjuntos de menhires muestran marcadores de las posiciones singulares del Sol y la Luna en sus horizontes (Thom 1967, 1971; Ruggles 1999). En nuestra opinión, este hecho podría deberse a dos motivos: a) los pueblos megalíticos de la península ibérica no buscaban marcadores astronómicos alrededor de sus monumentos; b) a un sesgo en los estudios arqueoastronómicos de los megalitos ibéricos debido a que se hayan centrado en la medición de las orientaciones de los corredores y no en el análisis de sus horizontes. Aunque esta última posibilidad podría ser cierta en el caso de, quizás, parte de los estudios de Hoskin (que se dedicó a obtener el máximo número de medidas precisas de la orientación de dólmenes y sepulcros megalíticos a través del Mediterráneo), este no es generalmente el caso de estudios posteriores como los realizados, por ejemplo, por J. A. Belmonte y A. C. González García, muy preocupados en la imbricación de los monumentos en el paisaje.

La presencia de marcadores astronómicos proporciona pistas acerca de la motivación en la selección del emplazamiento sobre el que se construyeron los monumentos prehistóricos, lo que constituye una información muy relevante. La presencia de un marcador indica que el lugar de construcción fue seleccionado 


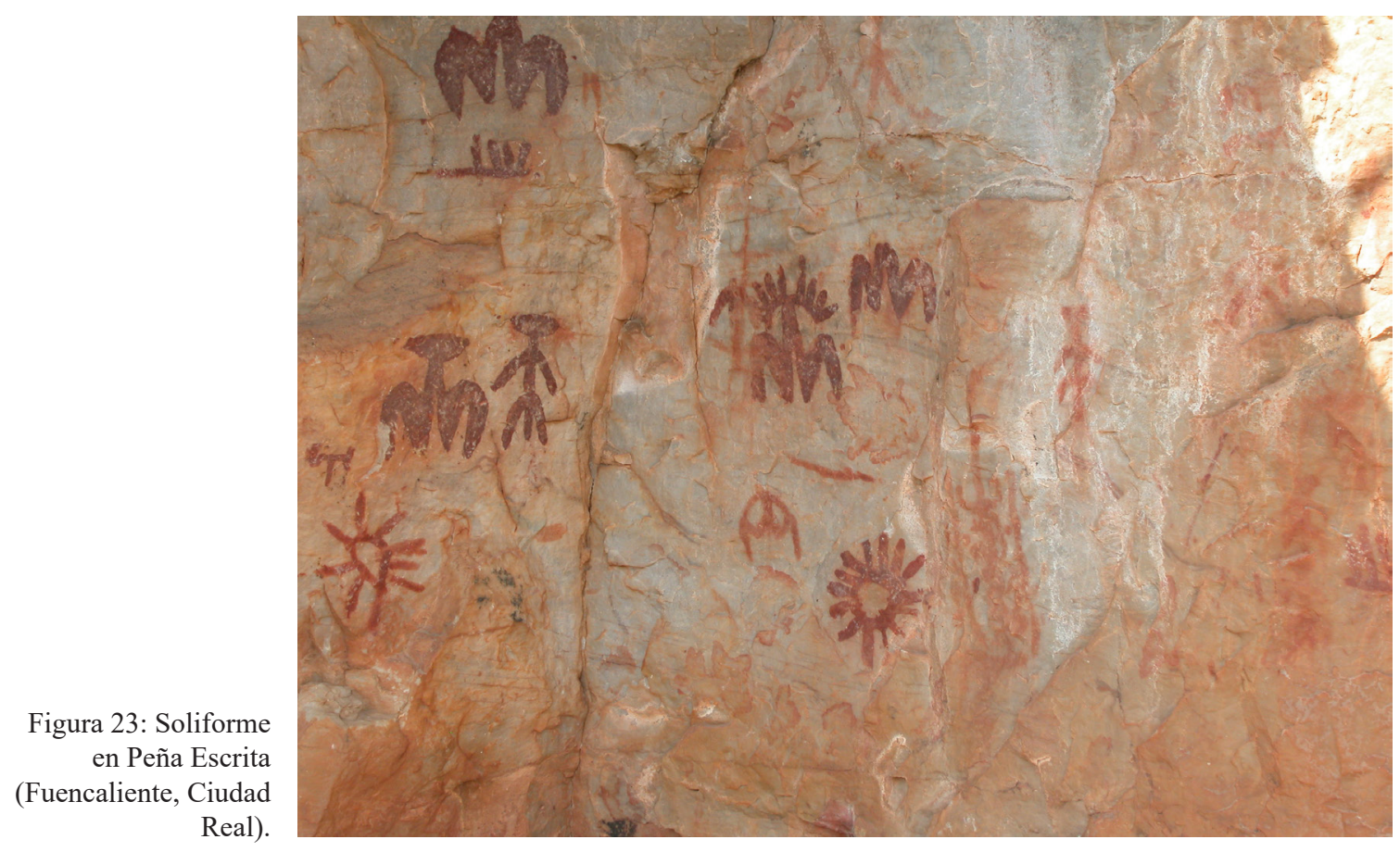

debido a que justo desde esa posición se observaba el fenómeno astronómico singular. Por otra parte, en ausencia de un marcador, podemos argumentar que el monumento fue construido en un lugar preciso debido a cualquier otro motivo no astronómico y que la orientación de su corredor (astronómica o no) se debió establecer a posteriori. Por lo tanto, parece que Castillejo del Bonete fue construido en un lugar seleccionado por la presencia del llamativo marcador de la salida del Sol en el solsticio de invierno y sobre una cueva con una orientación cercana a la solsticial. El ya fuerte significado astronómico del monumento se reforzó aún más a través de la alineación deliberada de algunos de sus corredores y accesos. Lo más probable es que todas estas relaciones astronómicas contribuyeran a potenciar extraordinariamente el carácter sagrado de un sitio que conjuga elementos ctónicos y cósmicos: monumentos funerarios, una cueva y fuertes relaciones solares. Un intrincado complejo de elementos simbólicos que proporciona una vía para ahondar en el mundo simbólico de la Prehistoria Reciente de las tierras manchegas. Estos resultados son convergentes con las propuestas de Escacena basadas en el análisis de elementos decorativos en cerámicas calcolíticas de la península ibérica. Según este autor, los habitantes de la Edad de Cobre peninsular participaron "de una interpretación del cielo similar a la que poseyeron otras culturas del Mediterráneo" que posiblemente ya se configuró desde el
Neolítico. Este autor también propone que la asociación de dichos conocimientos astrales con el mundo funerario se observa tanto en los ajuares de las tumbas como en las orientaciones astronómicas de muchas de ellas. La razón de esta asociación celeste y funeraria habría que encontrarla, según dicho investigador, en la creencia en el "destino ultraterreno del hombre" (Escacena Carrasco 2011-12: 191).

El elemento astronómico indicado por el marcador de Castillejo del Bonete, el solsticio de invierno, tiene una enorme carga simbólica, marca el momento del año en que el Sol alcanza su posición más meridional y comienza el alargamiento del día con respecto a la noche. Es el momento concreto del ciclo solar identificado como la victoria del astro rey frente a la oscuridad del invierno y del renacer de la naturaleza. Orientaciones y marcadores del orto u ocaso solar en el solsticio de invierno son relativamente frecuentes en estructuras megalíticas europeas de carácter ritual y funerario, como por ejemplo el círculo de piedras de Stonehenge (Wiltshire, Reino Unido), cuyas estructuras más antiguas se datan alrededor del 2500 a.C. y presentan un eje de simetría orientado hacia el ocaso del solsticio de invierno (Parker Pearson 2012; Ruggles 1999; Thom 1967 y 1971). En este momento del año se realizaban en Stonehenge y alrededores grandes festejos multitudinarios, según los últimos datos arqueológicos recopilados en la zona. Otro yacimiento emblemático es el 
impresionante sepulcro megalítico de Newgrange (Donore, Irlanda), construido entre el 3300 y 2900 a.C. (O’Kelly 1982). Su largo corredor presentaba una alineación perfecta hacia el orto solar en el solsticio de invierno en la época de su construcción.

Los conceptos de vida-muerte, nacimiento o renacimiento de divinidades solares han sido vinculados al solsticio en distintas culturas prehistóricas, protohistóricas y de la Antigüedad de las que tenemos constancia que desarrollaron calendarios cíclicos. La existencia de la creencia en una divinidad solar que muere y resucita en los solsticios ha sido argumentada para el Occidente del Mediterráneo en el III y II milenios, tradición que se podría haber reflejado en los denominados altares helioscópicos del mundo tartésico-fenicio (Escacena Carrasco 2009: 97 y 2016: 114). Solo en Europa contamos con casi tantas celebraciones en torno al solsticio de invierno como culturas han existido, como las bien conocidas fiestas solsticiales en los mundos celta y griego. También en el mundo romano tenemos la importante fiesta del Dies Natalis Invicti Solis, que se celebraba el primer día tras aquellos en que el Sol parecía detenerse alrededor del solsticio de invierno y en que la duración de la luz del día comienza a aumentar, lo que era interpretado como el "nacimiento" del astro. Estas ancestrales fiestas solsticiales se han prolongado hasta la era cristiana, aunque con otros significados y características, de forma tal que la celebración de la Navidad actual tiene un más que posible origen en estas antiguas festividades paganas. Los yacimientos estudiados en el presente trabajo constituyen unas de las primeras evidencias de la importancia simbólica del solsticio de invierno en el mundo funerario y ritual de las culturas prehistóricas de la península ibérica.

Finalmente, los corredores de las tumbas de Bocapucheros tienen una orientación diferente al resto de yacimientos estudiados en este trabajo, lo que sugeriría que son producto de una tradición también diferente. Una interpretación astronómica de su orientación podría ser su relación con el orto, culminación y ocaso de las estrellas de la Cruz del Sur. También el Corredor 2 de Castillejo del Bonete podría estar relacionado con el orto de estas estrellas u otras cercanas y muy brillantes como Rigil Kentaurus ( $\alpha$ Cen). Hoskin (2001) encontró orientaciones similares en una muestra de templos megalíticos de la isla de Malta (comenzados a construir alrededor del 3600 a.C.) y en la mayor parte de los santuarios talayóticos de Menorca y Mallorca (fechados entre 1300 y 800 a.C.), proponiendo que los ortos y ocasos de las estrellas antes mencionadas podrían ser los objetivos de dichos patrones de orientación. Hay que recordar que la Cruz del Sur y la zona alrededor de Rigil Kentaurus, muy cercanas en el cielo, eran las constelaciones más brillantes del extremo meridional de la bóveda celeste observable desde las llanuras manchegas en torno al 2000 a.C. Apenas se levantarían un máximo de entre $10^{\circ}$ y $15^{\circ}$ sobre el horizonte y serían unos indicadores excelentes del punto cardinal sur, algo parecido a nuestra estrella polar para el norte, aunque solo visibles durante una parte de la noche y en distintos momentos a lo largo del año. Alrededor del cambio de Era, estas estrellas quedaron ocultas bajo el horizonte debido a la precesión de los equinoccios, siendo completamente invisibles en los cielos manchegos en la actualidad.

\section{CONCLUSIONES}

Los resultados de este estudio indican el extraordinario interés arqueoastronómico del complejo monumental tumular de Castillejo del Bonete, que puede ser calificado de 'monumento solar'. Esta construcción prehistórica presenta un marcador del orto solar en el solsticio de invierno muy llamativo y preciso sobre el rasgo topográfico más conspicuo de todo el horizonte que rodea al yacimiento: la Peña del Cambrón. Varios corredores del monumento disponen de orientaciones con posible significado astronómico y/o topográfico. Resulta especialmente significativo que los corredores B y 1 (así como las galerías de la cueva que se extienden por debajo de estos corredores) se encuentran orientados hacia el orto y ocaso, respectivamente, del Sol en el solsticio de invierno; el mismo momento del año en que se produce el orto sobre El Cambrón. Otros corredores parecen presentar también orientaciones respecto a los ejes cardinales e incluso hacia el orto solar del solsticio de verano.

Los resultados para la necrópolis de Cerro Ortega y la motilla del Azuer, aunque mucho menos llamativos, también apuntan el mismo evento astronómico.

Como resultado podemos decir que el solsticio de invierno debió jugar un papel importante en el simbolismo religioso y/o funerario para las comunidades prehistóricas en el territorio estudiado.

\section{Agradecimientos}

Al Instituto Geológico y Minero de España, y en especial a Miguel Mejías Moreno, Investigador Principal del proyecto Investigación paleoclimática, hidrogeológica, geofísica y arqueoastronómica del más antiguo 
sistema de captación de agua subterránea de la Península Ibérica: la prehistórica 'Cultura de las Motillas de La Mancha', cofinanciado al 50\% por la Junta de Comunidades de Castilla-La Mancha (DGC/SPA; SBPLY/14180601/000031).

Al Ayuntamiento de Terrinches, en especial al principal impulsor de los trabajos en Castillejo del Bonete, su alcalde Nicasio Peláez.

A Jaime Moraleda Sierra, Carlos Barrio Aldea, Bienvenido Maquedano Carrasco, Juan Rozas Blanco, José Luis Fuentes Sánchez, Juan Gallego-Naturaletra y Audio\&Visual Factory por el diverso material gráfico empleado en este trabajo.

\section{BIBLIOGRAFÍA}

Aranda Jiménez, G.; Fernández García, S.; Haro Navarro, M.; Molina González, F.; Nájera Colino, T. y Sánchez Romero, M. (2008): “Water control and cereal management on the Bronze Age Iberian Peninsula: la motilla del Azuer". Oxford Journal of Archaeology 27 (3): 241 - 259.

Barrio Aldea, C. y Maquedano Carrasco, R. (2000): "La necrópolis calcolítica de Cerro Ortega (Villanueva de la Fuente)", en L. Benítez de Lugo (ed.), El Patrimonio arqueológico de Ciudad Real. Métodos de trabajo y actuaciones recientes: 67-86. Valdepeñas (Ciudad Real), Universidad Nacional de Educación a Distancia.

Belmonte, J. A. y Hoskin, M. (2002): Reflejo del Cosmos. Atlas de arqueoastronomía del Mediterráneo antiguo.. Madrid, Equipo Sirius S.L.

Benítez de Lugo Enrich, L.; Álvarez García, H.J.; Fernández Martín, S.; Mata Trujillo, E.; Moraleda Sierra, J.; Palomares Zumajo, N.; Odriozola Lloret, C.; Morgado Rodríguez, A. y Salazar García, D.C. (2014a): "Castillejo del Bonete (Terrinches, Ciudad Real): Un complejo tumular prehistórico de la cultura de las Motillas en el Alto Guadalquivir". Menga. Revista de Prehistoria de Andalucía 5: 151-173.

Benítez de Lugo Enrich, L.; Mejías Moreno, M.; López Gutiérrez, J.; Álvarez García, H.J.; Palomares Zumajo, N.; Mata Trujillo, E.; Moraleda Sierra, J.; Menchén Herreros, G.; Fernández Martín, S.; Salazar-García, D.C.; Odriozola Lloret, C.; Benito Sánchez, M. y López Sáez, J.A. (2014b): “Aportaciones hidrogeológicas al estudio arqueológico de los orígenes del Bronce de La Mancha: la cueva monumentalizada de Castillejo del Bonete (Terrinches,
Ciudad Real-España)". Trabajos de Prehistoria 71 (1): 76-94. Doi: 10.3989/tp.2014.12125.

Benítez de Lugo Enrich, L.; Álvarez García, H.J.; Palomares Zumajo, N.; Mata Trujillo, E. y Moraleda Sierra, J. (2014-2015): "Investigación y gestión de un complejo monumental prehistórico en el borde meridional de la Meseta: Castillejo del Bonete (Terrinches, Ciudad Real). Quince años de intervenciones arqueológicas (2003-2015)". Arse 48-49: 173-218.

Benítez de Lugo Enrich, L. y Mejías Moreno, M. (2015): "La prehistórica Cultura de las Motillas: nuevas propuestas para un viejo problema". Veleia 32: 111-124. Doi: 10.1387/veleia.14981.

Benítez de Lugo Enrich, L.; Palomares Zumajo, N.; Fernández Martín, S.; Mata Trujillo, E.; Menchén Herreros, G.; Montero Ruiz, I.; Moraleda Sierra, J.; Morgado Rodríguez, A.; Álvarez García, H.J.; Sánchez, B.; Odriozola Lloret, C.; Ruiz-Alonso, M. y Salazar-García, D.C. (2015a): "Paleoecología y cultura material en el complejo tumular prehistórico de Castillejo del Bonete (Terrinches, Ciudad Real): estudio analítico y contexto cultural". Menga, Revista de Prehistoria de Andalucía 6: 118-147.

Benítez de Lugo Enrich, L.; Schuhmacher, T.X.; Palomares Zumajo, N.; Álvarez García, H.J.; Mata Trujillo, E.; Moraleda Sierra, J.; Menchén Herreros, G. y Salazar-García, D.C. (2015b): "Marfil para los muertos en la Cultura de las Motillas: los botones de Castillejo del Bonete (Terrinches, Ciudad Real)". Madrider Mitteilungen 56: 40-61.

Benítez de Lugo Enrich, L. y Mejías Moreno, M. (2016): "Hidrogeología y captación de aguas en La Mancha durante la Prehistoria: la gestión de los recursos hídricos durante la Edad del Bronce en la Cultura de las Motillas". Archivo de Prehistoria Levantina 31: 137-168.

Benítez de Lugo Enrich, L. y Mejías Moreno, M. (2017): “"'The hydrogeological and paleoclimatic factors in Bronze Age Motillas Culture of La Mancha: the first hydraulic culture in Europe". Hydrogeology Journal, 25 (7): 1931-1950. DOI: https:// doi.org/10.1007/s10040-017-1607-z

Benítez de Lugo Enrich, L. (2018): "Rituales funerarios neolíticos, calcolíticos y de la Edad del Bronce en la provincia de Ciudad Real: Cerro Ortega (Villanueva de la Fuente) y Castillejo del Bonete (Terrinches)". Anejos Cuadernos de Prehistoria y Arqueología de la Universidad Autónoma de Madrid 3 (Homenaje a Isabel Rubio de Miguel).

Caballero Klink, A. (1983): La pintura rupestre esquemática de la vertiente septentrional de Sierra 
Morena (provincia de Ciudad Real) y su contexto arqueológico. Estudios y Monografías del Muso de Ciudad Real 9. 2 vols. Ciudad Real., Museo de Ciudad Real.

Cerdeño Serrano, Ma L.; Rodríguez Caderot, G.; Moya Maleno, P.R.; Ibarra Jiménez, A. u Herrero Calleja, S. (2006): "Los estudios de arqueoastronomía en España: estado de la cuestión". Trabajos de Prehistoria, 63 (2): 13-34.

Escacena Carrasco, J.L. (2009): "La Érgesis de Melqart. Hipótesis sobre una teología solar cananea". Complutum 20 (2): 95-120.

Escacena Carrasco, J.L. (2011-12): “El firmamento en un cuenco de cerámica. Viaje a las ideas calcolíticas sobre la bóveda celeste". Cuadernos de Prehistoria y Arqueología de la Universidad Autónoma de Madrid 37-38: 153-194.

Escacena Carrasco, J.L. (2016): "Rasguños faciales de luto, o sobre el 'tatuaje' de los idolillos calcolíticos hispanos”, en J. García Sánchez, I. Mañas Romero y F. Salcedo Garcés (eds.), Jornada Científica dedicada a José María Luzón Nogué: 99-116. Madrid, Universidad Complutense de Madrid.

Esteban, C. y Benítez de Lugo Enrich, L. (2016): "Orientaciones Astronómicas en el oppidum Oretano del Cerro de las Cabezas (Valdepeñas, Ciudad Real)". Trabajos de Prehistoria 73 (2): 268-283. DOI: https://doi.org/10.3989/tp.2016.12173

Esteban, C. y Moret, S. (2006): “Ciclos de tiempo en la cultura ibérica: La orientación astronómica en el templo del Tossal de Sant Miquel de Llíria". Trabajos de Prehistoria 63 (1): 167-178.

Fernández Martín, S.; Benítez de Lugo Enrich, L. y Palomares Zumajo, N. (2015): "La cerámica del yacimiento arqueológico Castillejo del Bonete (Terrinches, Ciudad Real). Estudio morfológico y tecnológico". Complutum 26: 133-152. DOI: http:// dx.doi.org/10.5209/rev_CMPL.2015.v26.n1.49344

Fernández Rodríguez, M. (2003): Las pinturas rupestres esquemáticas del Valle de Alcudia y Sierra Madrona. Ciudad Real, Mancomunidad de municipios del Valle de Alcudia y Sierra Madrona.

Gil Pitarch, P.; Miquel Feucht, M.J.; Negre Muñoz, M.C.; Polo Cerdá, M. y Villalaín Blanco, J.D. (1999): "Estudio antropológico y paleopatológico de los restos óseos del yacimiento neolítico de Villanueva de la Fuente (Ciudad Real)". II Congrés del Neolític a la Península Ibèrica. SagvuntumPlav Extra 2: 387-391.

González-García, A. C. (2009): "Statistical Analysis of Iberian Peninsula Megaliths Orientations", en J. A.
Rubiño-Martín, J. A. Belmonte, F. Prada y A. Alberdi (eds.), Cosmology Across Cultures. ASP Conference Series, 409: 354-358. San Francisco. Astronomical Society of the Pacific.

González Martín, J.A. (2016): "Recensión a: Arqueología, hidrogeología y medio ambiente en la Edad del Bronce de La Mancha. La Cultura de las Motillas. Ministerio de Economía y CompetitividadInstituto Geológico y Minero de España. Madrid. ISBN: 978-84-7840-972-3". Cuadernos de Prehistoria y Arqueología de la Universidad Autónoma de Madrid 42: 224-228.

Gutiérrez Sáez, C.; Gómez Laguna, A.J. y Ocaña Carretón, A. (2000): 'El enterramiento múltiple del Abrigo de Cueva Maturras (Argamasilla de Alba)", en L. Benítez de Lugo Enrich (ed.), El Patrimonio arqueológico de Ciudad Real. Métodos de trabajo y actuaciones recientes: 43-65. Valdepeñas (Ciudad Real), Universidad Nacional de Educación a Distancia.

Gutiérrez Sáez, C.; Gómez Laguna, A.J. y Ocaña Carretón, A. (2002): "Fuego y ritual en el enterramiento colectivo de Cueva Maturras (Argamasilla de Alba, Ciudad Real)", en M. Rojo Guerra y M. Kunst (eds.), Sobre el significado del fuego en los rituales funerarios del Neolítico: 99-126. Valladolid, Universidad de Valladolid.

Hoskin, M. (2001): Tombs, temples and their orientations. Bognor Regis. Ocarina Books.

López Sáez, J.A.; Abel Schaad, A.; Pérez Díaz, S.; Blanco González, A.; Alba Sánchez, F. Dorado, M.; Ruiz Zapata, B.; Gil García, M.J.; Gómez González, C. y Franco Múgica, F. (2014): "Vegetation history, climate and human impact in the Spanish Central System over the last 9000 years". Quaternary International 353: 98-122. DOI: https://doi. org/10.1016/j.quaint.2013.06.034

Martín Morales, C.; Fernández Miranda, M.; Fernández Posse, Ma . D. y Gilman, A. (1993): “The Bronze Age of La Mancha". Antiquity 67: 23-45.

Mejías Moreno, M.; Benítez de Lugo Enrich, L.; López Sáez, J.A. y Esteban López, C. (eds.) (2015): Arqueología, hidrogeología y medio ambiente en la Edad del Bronce de La Mancha. La Cultura de las Motillas. Madrid, Ministerio de Economía y Competitividad-Instituto Geológico y Minero de España.

Molina González, F.; Nájera Colino, T.; Aranda Jiménez, G.; Sánchez Romero, M. y Haro Navarro, M. (2005): "Recent fieldwork at the Bronze Age 
fortified site of Motilla del Azuer (Daimiel, Spain)". Antiquity 79 (306): 223-235.

Montero Ruiz, I.; Benítez de Lugo Enrich, L.; Álvarez García, H.J.; Gutiérrez Neira, P.C.: Murillo Barroso, M.; Palomares Zumajo, N.; Menchén Herreros, G.; Moraleda Sierra, J. y Salazar-García, D.C. (2014): "Cobre para los muertos. Estudio arqueométrico del material metálico procedente del monumento megalítico prehistórico Castillejo del Bonete (Terrinches, Ciudad Real-España)". Zephyrus LXXIII: 109-132. DOI: http://dx.doi.org/10.14201/ zephyrus201473109132

Nájera Colino, T.: Molina González, F.; Jiménez Brobeil, S.; Sánchez Romero, M.; Al Oumaoui, I.; Aranda Jiménez, G.; Delgado Huertas, A. y Laffranchi, Z. (2010): "La población infantil de la motilla del Azuer: Un estudio bioarqueológico". Complutum 21: 69-102.

Nájera Colino, T.; Jiménez Brobeil, S.; Molina González, F.; Delgado Huertas, A. y Laffranchi, Z. (2012): "La aplicación de los métodos de la Antropología Física a un yacimiento arqueológico: la motilla del Azuer". Cuadernos de Prehistoria de la Universidad de Granada 22: 149-183.

Odriozola Lloret, C.; Benítez de Lugo Enrich, L.; Villalobos García, R.; Martínez-Blanes, J.M.; Avilés, M.A.; Palomares Zumajo, N.; Benito Sánchez, M.; Barrio Aldea, C. y Salazar García, D.C. (2016): "Personal body ornamentation on the Southern Iberian Meseta: An archaeomineralogical study". Journal of Archaeological Sciences: Reports, 5: 156-167. DOI: https://doi.org/10.1016/j. jasrep.2015.11.021

O'Kelly, M.J. (1982): Newgrange: Archaeology, Art and Legend, London, Thames y Hudson.
Parker Pearson, M. (2012): Stonehenge: Exploring the Greatest Stone Age Mistery. London \& New York, Simon \& Schuster.

Polo Cerdá, M.; Negre Muñoz, M.C.; Miquel Feutch, M.J.: Gil Pitarch, P. y Villalaín Blanco, J.D. (1999): "Estudio paleodontológico y paleonutricional de los restos óseos del yacimiento neolítico de Villanueva de la Fuente (Ciudad Real)". II Congrés del Neolític a la Península Ibèrica. Sagvuntum-Plav Extra 2: 379-385.

Polo Martín, E.; Bueno Ramírez, P.; Balbín Behrmann, R. De; Benítez de Lugo Enrich, L.; Palomares Zumajo, N. (2015a): "Manifestaciones gráficas en la Cueva-Sima del Castillejo del Bonete (Terrinches, Ciudad Real)". Arqueología del Interior Peninsular-Arpi 2: 90-107.

Ruggles, C. (1999): Astronomy in Prehistoric Britain and Ireland. New Haven \& London, Yale University Press.

Salazar García, D.C; Benítez de Lugo Enrich, L.; Álvarez García, H.J. y Benito Sánchez, M. (2013): "Estudio diacrónico de la dieta de los pobladores antiguos de Terrinches (Ciudad Real) a partir del análisis de isótopos estables sobre restos óseos humanos". Revista Española de Antropología Física 34: 6-14.

Thom, A. (1967): Megalithic Sites in Britain. Oxford, Oxford University Press.

Thom, A. (1971): Megalithic Lunar Observatories. Oxford, Oxford University Press.

Torres Mas, M. (2015): "La motilla de El Azuer: un yacimiento de interés cultural en Daimiel (Ciudad Real)". III Jornadas de Historia de Daimiel. Ayuntamiento de Daimiel. Daimiel: 31-44. 